\title{
Dose study of the multikinase inhibitor, LY2457546, in patients with relapsed acute myeloid leukemia to assess safety, pharmacokinetics, and pharmacodynamics
}

\author{
This article was published in the following Dove Press journal: \\ Cancer Management and Research \\ 12 May 2011 \\ Number of times this article has been viewed
}

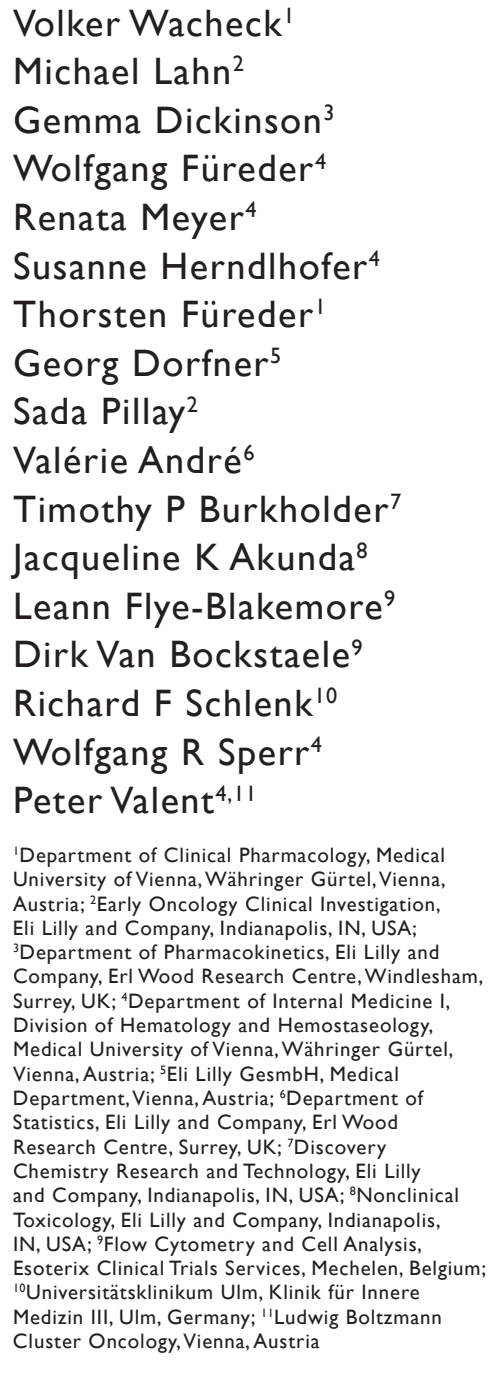

Correspondence: Peter Valent

Department of Internal Medicine I, Division of

Hematology and Hemostaseology, Medical University of Vienna, Währinger Gürtel 18-20, 1090 Vienna, Austria

Tel +431404004409

$\mathrm{Fax}+43 \quad 14026930$

Email peter.valent@meduniwien.ac.at
Background: Acute myeloid leukemia (AML) is a life-threatening malignancy with limited treatment options in chemotherapy-refractory patients. A first-in-human dose study was designed to investigate a safe and biologically effective dose range for LY2457546, a novel multikinase inhibitor, in patients with relapsed AML.

Methods: In this nonrandomized, open-label, dose escalation Phase I study, LY2457546 was administered orally once a day. Safety, pharmacokinetics, changes in phosphorylation of target kinases in AML blasts, and risk of drug-drug interactions (DDI) were assessed.

Results: Five patients were treated at the starting and predicted minimal biologically effective dose of $50 \mathrm{mg} /$ day. The most commonly observed adverse events were febrile neutropenia, epistaxis, petechiae, and headache. The majority of adverse events (81\%) were Grade 1 or 2. One patient had generalized muscle weakness (Grade 3), which was deemed to be a dose-limiting toxicity. Notably, the pharmacokinetic profile of LY2457546 showed virtually no elimination of LY2457546 within 24 hours, and thus prevented further dose escalation. No significant DDI were observed. Ex vivo flow cytometry studies showed downregulation of the phosphoproteins, pcKIT, pFLT3, and pS6, in AML blasts after LY2457546 administration. No medically relevant responses were observed in the five treated patients.

Conclusion: No biologically effective dose could be established for LY2457546 in chemotherapy-resistant AML patients. Lack of drug clearance prevented safe dose escalation, and the study was terminated early. Future efforts should be made to develop derivatives with a more favorable pharmacokinetic profile.

Keywords: multikinase inhibitor, pharmacokinetics, safety, acute myeloid leukemia, pharmacodynamics

\section{Introduction}

Acute myeloid leukemia (AML) is a heterogeneous disorder of hemopoietic stem cells. ${ }^{1}$ Despite improved treatment of AML in recent years, the outcome remains dismal, with only approximately $30 \%$ of patients showing long-term survival. ${ }^{2}$ Factors determining survival include age, cytogenetic aberrations, number of previous antileukemia treatments, and molecular defects in leukemic cells. ${ }^{1-3}$ In patients with a normal karyotype, mutations in certain oncogenic kinases, such as FLT3 or KIT, ${ }^{4}$ determine the prognosis in AML. ${ }^{3,5-15}$ Blast cell proliferation and dissemination may be triggered by additional factors, including expression of certain homing receptors and the bone marrow microenvironment. ${ }^{16-23}$

A number of pharmacologic approaches have been proposed to counteract leukemic cell growth in AML. A straightforward approach is to develop multikinase 
inhibitors acting on one or more critical signaling pathways associated with leukemic cell growth, proliferation, and/or differentiation. ${ }^{24}$ In fact, various multikinase inhibitors can simultaneously inhibit multiple signaling pathways involved in AML cell growth and survival..$^{25-34}$

LY2457546 is a novel multikinase inhibitor with properties similar to LY2401402, which was previously shown to have an antileukemic effect in MV4-11 cells containing an FLT3-ITD mutation. ${ }^{35,36}$ LY2457546 has a spectrum of kinase inhibition that is distinct from that of other multikinase inhibitors, including sunitinib. For example, LY2457546 inhibits several of the ephrins and
Tie- $2^{37}$ (Table 1). Based on this information, a pharmacokinetic/pharmacodynamic model was developed using in vitro and in vivo animal data to estimate the biologically effective dose range for LY2457546 in humans, ${ }^{38}$ and to identify a safe starting dose for a first-in-human dose-escalation study in patients with AML. Using this predictive model, the primary objective of this study was to confirm the safety and the biologically effective dose range of LY2457546 in patients with AML. As secondary objectives, we evaluated the pharmacokinetic profile of LY2457546 and changes in pharmacodynamic markers (such as changes in phosphoprotein expression in circulating AML blasts) after

Table I In vitro Inhibition Profile of LY2| 457546

\begin{tabular}{|c|c|c|c|c|c|}
\hline & & Human Kinases & LY2457546 & Sunitinib & Sorafenib \\
\hline & & \multicolumn{4}{|c|}{ Biochemical Inhibition Profile IC50 $(\mu \mathrm{M})$} \\
\hline & & FLT4 & 0.00156 & 0.00566 & 0.0261 \\
\hline & & RET & 0.00419 & 0.0485 & 0.0033 \\
\hline & & FLT3 & 0.0051 & 0.00659 & 0.105 \\
\hline & & EPHA5 & 0.0107 & 8.05 & 0.531 \\
\hline & & EPHB I & 0.0214 & 1.15 & 0.474 \\
\hline & & PDGF-Rb & 0.0257 & 0.0352 & 0.312 \\
\hline & & KDR & 0.028 & 0.0611 & 0.013 \\
\hline & & VEGF-R I & 0.0306 & 0.269 & 0.241 \\
\hline & & EPHA8 & 0.0335 & $>20$ & 0.214 \\
\hline & & VEGF-R3 & 0.0341 & 0.0323 & 0.0925 \\
\hline & & EPHA2 & 0.0374 & 9.38 & 0.276 \\
\hline & & EPHB4 & 0.0398 & 1.59 & 0.727 \\
\hline & & ЕРHB2 & 0.0457 & 3.13 & 0.854 \\
\hline & & cKIT & 0.0738 & 0.0756 & 0.966 \\
\hline & & EPHA3 & 0.0998 & 10.5 & 1.42 \\
\hline & & EPHA4 & 0.157 & 11.7 & 3.26 \\
\hline & & EPHA7 & 0.221 & 5.38 & 0.709 \\
\hline & & RAF & 0.264 & $>20$ & 0.0195 \\
\hline & & EPHAI & 0.616 & 7.08 & ND \\
\hline & & p70S6K & 75.9 & 92.3 & 75.6 \\
\hline & & $\begin{array}{l}\text { (percent inhibition a } \\
20 \mu \mathrm{M})\end{array}$ & & & \\
\hline \multicolumn{6}{|c|}{ Cell-Based Target Inhibition Assays IC50 (mM) } \\
\hline Cell line & Activator & $\begin{array}{l}\text { Phospho end } \\
\text { point }\end{array}$ & LY2457546 & Sunitinib & Sorafenib \\
\hline HUVEC & VEGF & pERK ${ }^{\mathrm{T} 202 Y 204}$ & 0.00205 & 0.0287 & ND \\
\hline MV4-II & constitutively active & pSTA $^{\text {TSY694 }}$ & 0.00039 & 0.00426 & ND \\
\hline HUVEC & VEGF & $\begin{array}{l}\text { PERKp }{ }^{\text {T202Y204 }} \\
\text { (with BSA) }\end{array}$ & 0.0414 & 0.0552 & 0.038 \\
\hline A2780 & PDGF & $\mathbf{p A K}^{\mathrm{TS} 473}$ & 0.0588 & 0.0169 & 1.33 \\
\hline $\begin{array}{l}\mathrm{CHO}- \\
\text { Clonell3 }\end{array}$ & $\begin{array}{l}\text { stable over-expression } \\
\text { of TIE2 }\end{array}$ & PTIE2 ${ }^{\text {Y99 }}$ & 0.166 & $>10$ & 0.327 \\
\hline $\begin{array}{l}\text { HEK293- } \\
\text { Clone } 25\end{array}$ & $\begin{array}{l}\text { stable over-expression } \\
\text { of EphB4 }\end{array}$ & pEphB4 ${ }^{\text {Y590/Y596 }}$ & 0.0091 & 3.013 & 0.337 \\
\hline \multicolumn{6}{|c|}{ Cell-Based Antiproliferation Assay IC50 ( $\mu \mathrm{M})$} \\
\hline & & & LY2457546 & Sunitinib & Sorafenib \\
\hline MV4-II & \multicolumn{2}{|c|}{ constitutively active (FLT3 ITD Mutation D835) } & 0.000339 & 0.0196 & 0.0117 \\
\hline
\end{tabular}

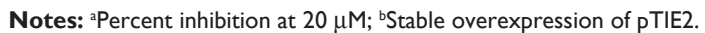

Abbreviations: HUVEC, human umbilical endothelial vascular cells; ND, not determined; BSA, bovine serum albumin. 


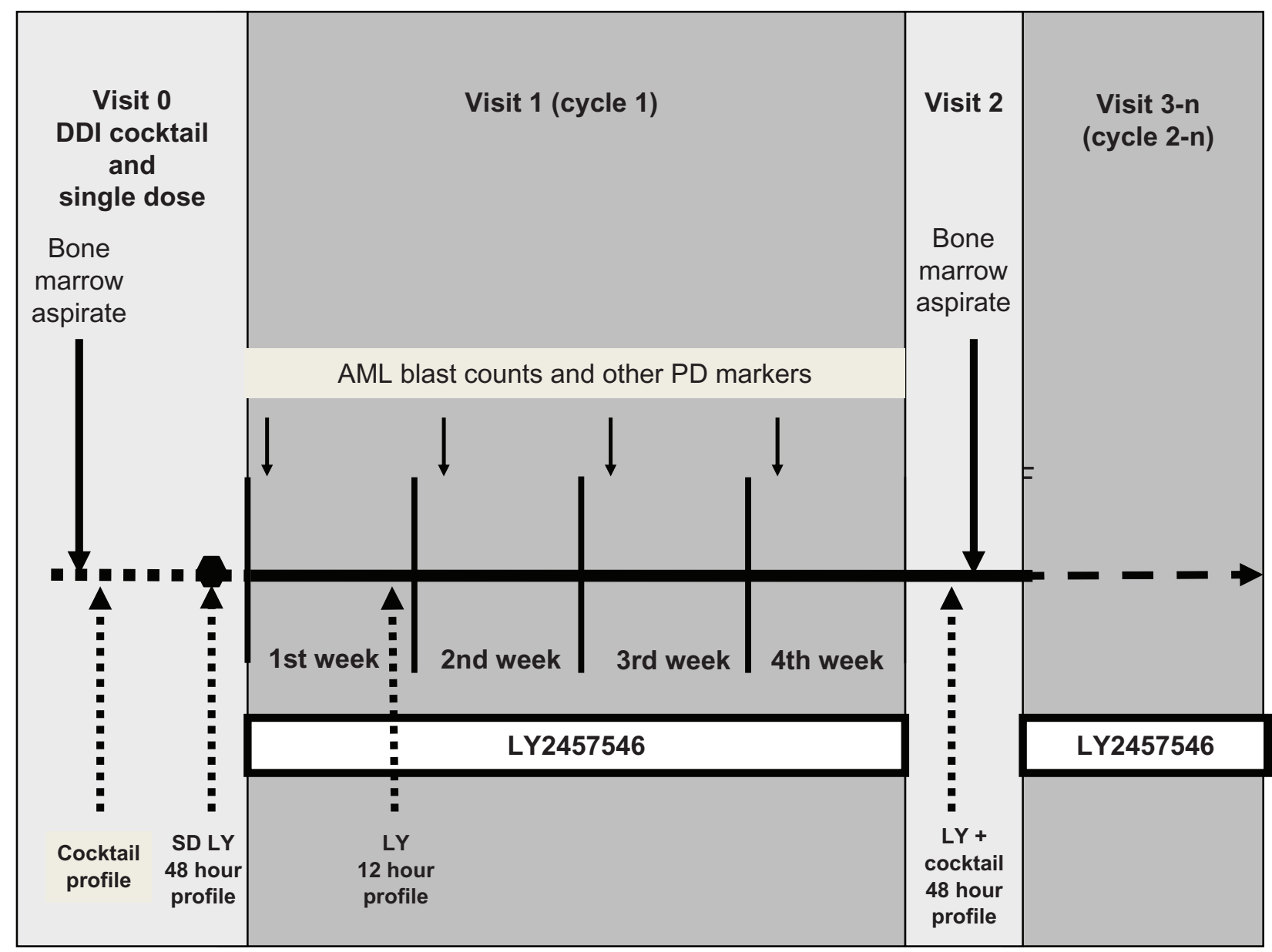

Figure I Design of the first-in-human dose study with LY2457546. To evaluate the safety, pharmacokinetics, DDI risk, and pharmacodynamic effects of single-dose (visit 0 ) and multiple-dose (visit I, visit 3n) administration of LY2457546, patients first underwent a bone marrow aspirate, which was repeated after multiple-dosing for four weeks (two weeks after amendment, visit 2). During visit I, patients' peripheral blast cell counts and changes in phosphoprotein expression were assessed daily and weekly, respectively. The DDI cocktail was administered prior to taking a single dose (approximately seven days prior to the single dose of LY2457546) and again after two or four weeks (after amendment) of multiple doses of LY2457546 (visit 2). The pharmacokinetic profile of LY2457546 was evaluated in the absence of the DDI cocktail as a single dose (48-hour profile) and again after one week of multiple dosing (12-hour profile).

Abbreviations: DDI, drug-drug interaction; AML, acute myeloid leukemia; LY, LY2457546.

LY2457546 administration. Moreover, the potential risk of drug-drug interactions by combining LY2457546 with drugs known to be metabolized by cytochrome P450 (CYP) 3A4, CYPP2D6, and CYP2C9 were assessed.

\section{Materials and methods}

\section{Study design}

This first-in-human monotherapy safety study was divided into three parts to evaluate a possible drug-drug interaction risk of LY2457546, and to confirm the predicted pharmacokinetic/pharmacodynamic relationship of LY2457546 in humans (Figure 1). The first part (visit 0) consisted of a single-dose, 48-hour pharmacokinetic profile evaluation of LY2457546 (from day day -2 to day 1) and a baseline assessment of a drug-drug interaction cocktail. The second part (visit 1) was a mul- tidose assessment for four weeks (for two weeks after an amendment) of daily oral administration of LY2457546. During visit 1, a 12-hour pharmacokinetic profile of LY2457546 was obtained. The third part (visit 2) evaluated the 48-hour pharmacokinetic profile of LY2457546 in the presence of the drug-drug interaction cocktail after LY2457546 was stopped. Treatment was resumed as daily dosing for the remainder of the study, provided the patient showed clinical benefit.

The study was approved by the ethics committee of the Medical University of Vienna and the Austrian Federal Ministry of Health according to the International Conference on Harmonization guidelines, the Declaration of Helsinki on clinical trials involving human subjects, the recommendation for conducting clinical first-in-human dose studies by the Committee For Medicinal Products For HumanUse (www.emea. 
europa.eu/pdfs/human/swp/2836707enfin.pdf from August 20, 2007, and the Austrian Medicinal Products Act (AMG).

\section{Enrolment criteria}

The inclusion criteria were: age at least 18 years; diagnosis of relapsed or refractory AML; ineligibility for bone marrow transplantation or induction/consolidation chemotherapy ${ }^{39} \geq 10 \%$ of blasts in peripheral blood at baseline; willingness to undergo two bone marrow aspirates during visits 0 and 2 to evaluate changes in phosphoprotein expression in AML blasts; recovery from the acute toxic effects of previous treatment; performance status 0 to 2 on the Eastern Cooperative Oncology Group scale; discontinuation of all previous therapies for cancer for at least 14 days (hydroxyurea used to control the peripheral blast cell count was permitted until 72 hours before study drug administration at visit 1 ); bilirubin $\leq 2 \times$ below the upper limit of normal, alanine aminotransferase and aspartate aminotransferase $\leq 5 \times$ upper limit of normal; serum creatinine $\leq 1.5 \times$ upper limit of normal; no known active renal disease; activated prothrombin time and prothrombin time at or below upper limit of normal. Male and female patients agreed to use a reliable method of birth control during dosing and for six months following the last dose of study drug. Females of childbearing potential had to have had a negative serum pregnancy test at least seven days prior to the first dose of study drug. Monthly pregnancy tests were conducted in accordance with Article 30 of the AMG. Finally, patients had to be compliant with all protocol-defined procedures and be able to swallow capsules.

Patients were excluded if they had acute promyelocytic leukemia as defined by World Health Organization criteria, ${ }^{39}$ chronic myeloid leukemia in blast crisis, leukemic involvement of the central nervous system (eg, signs, symptoms or a history of leukemic meningitis, must have had a negative lumbar puncture within two weeks of study enrolment), serious concomitant disorders (eg, active bacterial, fungal, or viral infection), active second primary malignancy that could affect study conduct or interpretation of study results, serious pre-existing medical conditions (eg, persistent history of occlusive coronary artery disease, uncontrolled hypertension with systolic $>140 \mathrm{mmHg}$ and diastolic $>90 \mathrm{mmHg}$, risk of bleeding due to active gastrointestinal bleeding or anticoagulant therapy, except for low-dose therapy to maintain patency of central venous access devices), major surgery within four weeks of study enrolment, positive test results for human immunodeficiency virus antibodies, hepatitis B surface antigen, or hepatitis $\mathrm{C}$ antibodies, and women who were pregnant or lactating.

\section{Drug formulation and schedule of administration}

LY2457546 was taken as a once-daily oral capsule in the morning before breakfast. All patients had been fasting for approximately eight hours prior to the LY2457546 dose and for two hours prior to dosing of the drug cocktail. After oral administration, patients were asked to wait for at least 60 minutes prior to having breakfast. For at least two weeks prior to the start of the study and until the final pharmacokinetic sample was collected, patients were requested to abstain from beverages containing grapefruit or pomelo fruit, and food containing broccoli, cabbage, cauliflower, turnips, collard, mustard, or charbroiled meats. If a patient continued taking dietary supplements, such as vitamins or St John's wort, these were recorded as comedication and considered in the interpretation of the pharmacokinetic data.

\section{Drug-drug interaction cocktail}

The drug-drug interaction cocktail consisted of midazolam $0.2 \mathrm{mg}$, dextromethorphan $30 \mathrm{mg}$, and tolbutamide $500 \mathrm{mg}$ as specific probes to assess the CYP3A4, CYP2D6, and CYP2C9 metabolic pathways, respectively. ${ }^{40-43}$

\section{Treatment assessment}

Investigators assessed baseline "toxicity" according to institutional and previously published guidelines, ${ }^{44}$ which included establishing baseline neutropenia and other bone marrow deficiencies as a result of AML. Assessment of dose-limiting toxicity was graded following the National Cancer Institute's Common Terminology Criteria for Adverse Events (CTCAE) version 3.0. The following adverse events were deemed to be dose-limiting toxicities if they were likely to be drug-related: $\geq$ Grade 3 nonhematological toxicity (except for nausea/vomiting without maximal symptomatic/prophylactic treatment), CTCAE Grade 3 or 4 febrile neutropenia, CTCAE Grade 3 infection with Grade 3 or 4 neutropenia, untreated diarrhea Grade $\geq 3$, CTCAE Grade 4 neutropenia or thrombocytopenia until four weeks after the end of the treatment course, unless the respective Grade 4 cytopenia was pre-existing. In patients who required platelet substitution to maintain a CTCAE Grade $<4$ before treatment, a CTCAE Grade 4 thrombocytopenia after treatment did not constitute a dose-limiting toxicity. 
Due to the cardiac toxicities observed with other multikinase inhibitors, the risks of developing Grade 3/4 QTc prolongation or increased blood pressure were evaluated. For QTc prolongation, the following dose-limiting toxicity definitions were used: any CTCAE Grade 4 QTc prolongation or three of six patients with CTCAE Grade 3 and a definitive association between QTc prolongation and LY2457546 exposure. Provided that other factors known to prolong QTc intervals had been minimized or excluded, assessment of QTc prolongation was based on Fridericia's corrected QTc evaluation (QTcF) at the end of each cohort. In the event that CTCAE Grade 3 QTc prolongation was observed (defined as an interval $>500 \mathrm{msec}$ or an increase of QTc of $>60 \mathrm{msec}$ from baseline with no medically significant symptoms), a confirmatory 12-lead electrocardiogram was required before LY2457546 doses were omitted until the QTc interval returned to $<500 \mathrm{msec}$ or below the $60 \mathrm{msec}$ upper boundary. In the event that CTCAE Grade 4 QTc prolongation was observed (defined as an interval $>500 \mathrm{msec}$ or an increase of QTc of $>60 \mathrm{msec}$ from baseline with lifethreatening signs or symptoms), patients would be considered for withdrawal from the study on the basis of dose-limiting toxicity.

\section{Dose escalation}

Dose escalation was planned up to the maximum tolerated dose. The decision to dose-escalate to the next cohort and dose level was planned on the basis of safety and available pharmacokinetic and pharmacodynamic data from the previous dose cohort. This decision was planned to occur in agreement with the investigators and sponsor. Written notification of this decision was to be sent to the site and appropriate institutional ethics committee. No intrapatient dose escalation beyond the original assigned cohort was permitted.

At the end of the first cohort, the pharmacokinetic profiles for the LY2457546 and drug cocktail were reviewed to confirm the predicted exposures for the following doses. The starting dose was $50 \mathrm{mg} /$ day, and the maximum planned dose was $500 \mathrm{mg} /$ day. The first cohort included three patients. For all subsequent doses where a pharmacological effect was expected, the cohort size was increased to six patients. All patients in a given cohort had to complete the first multidose cycle prior to enrolling patients at the next dose level. If two or more of six patients experienced a dose-limiting toxicity at any dose level, the maximum tolerated dose was exceeded and dose escalation ceased. For QTc prolongation, Grade 3 QTc prolongation was required in three of six pts to declare a dose-limiting toxicity, while all Grade 4 QTc prolongations were declared as dose-limiting toxicity.

\section{Pharmacokinetic assessment}

Pharmacokinetic parameters were analyzed using standard, noncompartmental methods of analysis (WinNonlin Enterprise, version 5.2). It was planned to calculate the following: time to maximum concentration $\left(\mathrm{T}_{\max }\right)$, maximum plasma concentration $\left(\mathrm{C}_{\max }\right)$, area under the plasma concentration versus time curve (AUC), and oral clearance following LY2457546 administration.

\section{Pharmacodynamic assessment}

Based on the predictive pharmacokinetic/pharmacodynamic model, the biologically effective dose range was anticipated to be between $100 \mathrm{mg}$ and $400 \mathrm{mg}$. The recommended biologically effective dose should provide a minimum of $50 \%$ median inhibition of one or all phosphoproteins for 24 hours (the minimum requirement to declare a biologically effective dose would be based on pFLT3 inhibition), should provide durable AML blast reduction compared with baseline in at least half of the patients (for at least one month), and be lower than the maximum tolerated dose.

\section{Flow cytometry}

As previously described, blood samples were collected to evaluate phosphoprotein levels using flow cytometry. ${ }^{45}$ In order to ensure appropriate assessment of changes in phosphoprotein expression, samples had to be shipped within 48 hours to a central laboratory (Esoterix, Mechelen, Belgium) after blood or bone marrow aspirates were obtained. Upon arrival, cells were prepared for cytometric assessment, gated based on side versus forward scatter, and subsequently for CD45, CD34 (CD45-PerCP and CD34-PE, Becton Dickinson, San Jose, CA) and CD11b (CD11b-Pacific Blue, Beckman Coulter, Miami, FL, Esoterix custom conjugate) expression. This gating approach allowed the separation of four distinct subgroups, ie, $\mathrm{CD} 34^{+} \mathrm{CD} 11 \mathrm{~b}^{-}, \mathrm{CD} 34^{+} \mathrm{CD} 11 \mathrm{~b}^{+}$, CD34-CD11b-, and CD34-CD11 ${ }^{+}$. For each of these subgroups, the following phosphoproteins were determined with their respective isotype control (all antibodies were obtained from Cell Signaling Technology [CST], Danvers, MA): phospho-FLT3/CD135 (Y591-Alexa Fluor 647, CST, Esoterix custom conjugate); phospho-c-KIT/CD117 (Y719, No ST\#3391L, CST); phospho-p44/42 extracellular signaling-regulated kinase 1/2 (pERK1/2, T202/Y204, Alexa Fluor 647, No 4375, CST); phospho-AKT (S473-Alexa Fluor 647, No 4075, CST); phospho-phospho-tyrosine-Y100 
(pY100) (Alexa Fluor 488, No 9415, CST); phospho-S6 ribosomal protein (pS6) (S235/236-Alexa Fluor 647, CST, Esoterix custom conjugate). Phospho-STAT5 was determined along with isotype control using anti-phospho-STAT5 (Y694, No 612599, Becton Dickinson). The isotype controls used for the phosphoproteins were matched with the primary antibodies at the identical concentrations used in the assay. The phospho c-KIT (pcKIT) was developed using a goatantirabbit Alexa Fluor 647 (both used at $1 \mu \mathrm{g}$ per staining reaction). In all cases, the staining reactions were carried out in $50 \mu \mathrm{L}$ total volumes in phosphate-buffered saline with $3.4 \%$ bovine serum albumin.

Flow cytometry was performed on a 3-laser Becton Dickinson FACS-Canto-II cytometer with custom filter sets designed to optimize the collection of Alexa 647 and Alexa 700 signals, in lieu of tandem dyes. The instrument was set up using QC3 beads (Bangs Laboratories, Fishers, IN), Spherotech 1 peak Rainbow Mid-Range beads (Spherotech, Lake Forest, IL), and CaliBrite APC beads (Beckton Dickinson) for the daily monitoring of instrument performance within an accepted "window of analysis". Full spectrum fluorescent calibration particles (Spherotech) were also run with each assay to determine the molecules of equivalent fluorescence of the phosphoproteins. Each sample was analyzed using a direct data exchange link between WinList 6.0 (Verity Software House, Topsham, MA) and Microsoft Excel (Microsoft, Redmond, WA). All data gating, displaying, and processing were conducted in WinList.

\section{Antileukemia response assessment}

Based on the recent World Health Organization criteria, ${ }^{46}$ responses were determined by assessing bone marrow aspirates. In this study, we also considered a pharmacodynamic response if a sustained reduction in peripheral blast cell counts was observed (longer than four weeks).

\section{Results}

Five patients (A-E) were enrolled from February to August 2009 and received $50 \mathrm{mg}$ LY2457546 once daily. Except for one patient, all had an original diagnosis of primary AML. The median age of the patients was 68 years, with only one patient younger than 60 years (Table 2). The majority had been diagnosed with leukemia for at least 18 months. All patients had undergone at least a full regimen of induction chemotherapy. Prior to entering the trial, all patients had received hydroxyurea to control blast cell counts. Two patients had medically treated hypertension at study entry, which did not deteriorate as a result of LY2457546 administration.
Table 2 Baseline patient and disease characteristics $(n=5)$

\begin{tabular}{|c|c|c|}
\hline \multirow[t]{2}{*}{ Gender } & Male & 3 \\
\hline & Female & 2 \\
\hline \multirow[t]{2}{*}{ Age group (years) } & $\leq 60$ & I \\
\hline & $>60$ & 4 \\
\hline ECOG performance & 0 & 2 \\
\hline status & 1 & 3 \\
\hline \multirow[t]{3}{*}{ Pathological diagnosis } & Primary AML & 4 \\
\hline & Secondary AML & I \\
\hline & (myelodysplastic syndrome) & \\
\hline \multirow{2}{*}{$\begin{array}{l}\text { Time since initial } \\
\text { diagnosis (years) }\end{array}$} & $\leq 1.5$ & 4 \\
\hline & $>1.5$ & 1 \\
\hline \multirow{5}{*}{$\begin{array}{l}\text { Prior antileukemia } \\
\text { therapy }\end{array}$} & Induction only & 1 \\
\hline & Induction/consolidation & 4 \\
\hline & Number of regimen & \\
\hline & $\leq 1$ & 1 \\
\hline & $>1$ & 4 \\
\hline \multirow[t]{12}{*}{ Historical illness } & Prostate cancer & 3 \\
\hline & Cholelithiasis & 1 \\
\hline & Venous thrombosis & 2 \\
\hline & Diverticulosis & I \\
\hline & Duodenal ulcer & 1 \\
\hline & Facial paresis & 1 \\
\hline & Goiter & 1 \\
\hline & Invertebral disc protrusion & I \\
\hline & Myelodysplastic syndrome & 1 \\
\hline & Osteoarthritis & 1 \\
\hline & Pneunomia & 1 \\
\hline & Polymyalgia rheumatica & 1 \\
\hline \multirow[t]{5}{*}{ Karyotype } & $46, X X, t(9 ; 1 I)$ & Patient A \\
\hline & $46, \mathrm{XY}, \mathrm{t}(\mathrm{X} ; 2) / 47, \mathrm{XY}, \mathrm{t}(2 ; \mathrm{X})+9 / 46, \mathrm{XY}$ & Patient B \\
\hline & $47, X Y,+8 / 46, X Y$ & Patient C \\
\hline & 46,XY,del(II) & Patient D \\
\hline & 46,XX,del,(I2),del(20)/46,XX & Patient $\mathrm{E}$ \\
\hline
\end{tabular}

Abbreviations: AML, acute myeloid leukemia; ECOG, Eastern Cooperative Oncology Group.

During visit 1 , the first three patients were discontinued from treatment on days 17, 20, and 30. The first two patients were discontinued due to disease progression. The third patient (C) showed Grade 3 muscle weakness on day 10 which was considered to be drug-related and deemed a dose-limiting toxicity. Given the early discontinuation of the first three patients, the protocol was amended to shorten the first cycle to a 14-day cycle to obtain a pharmacokinetic profile after 14 days of multiple dosing of LY2457546. Two more patients (D, E) were treated after this amendment and were discontinued on days 7 and 17. The reason for discontinuation in these two patients was disease progression based on clinical symptoms. Three patients died a few days after discontinuation of LY2457546, primarily due to sepsis and progressive leukemia which was no longer controlled by post-study administration of hydroxyurea. In one of the five patients (B) we 

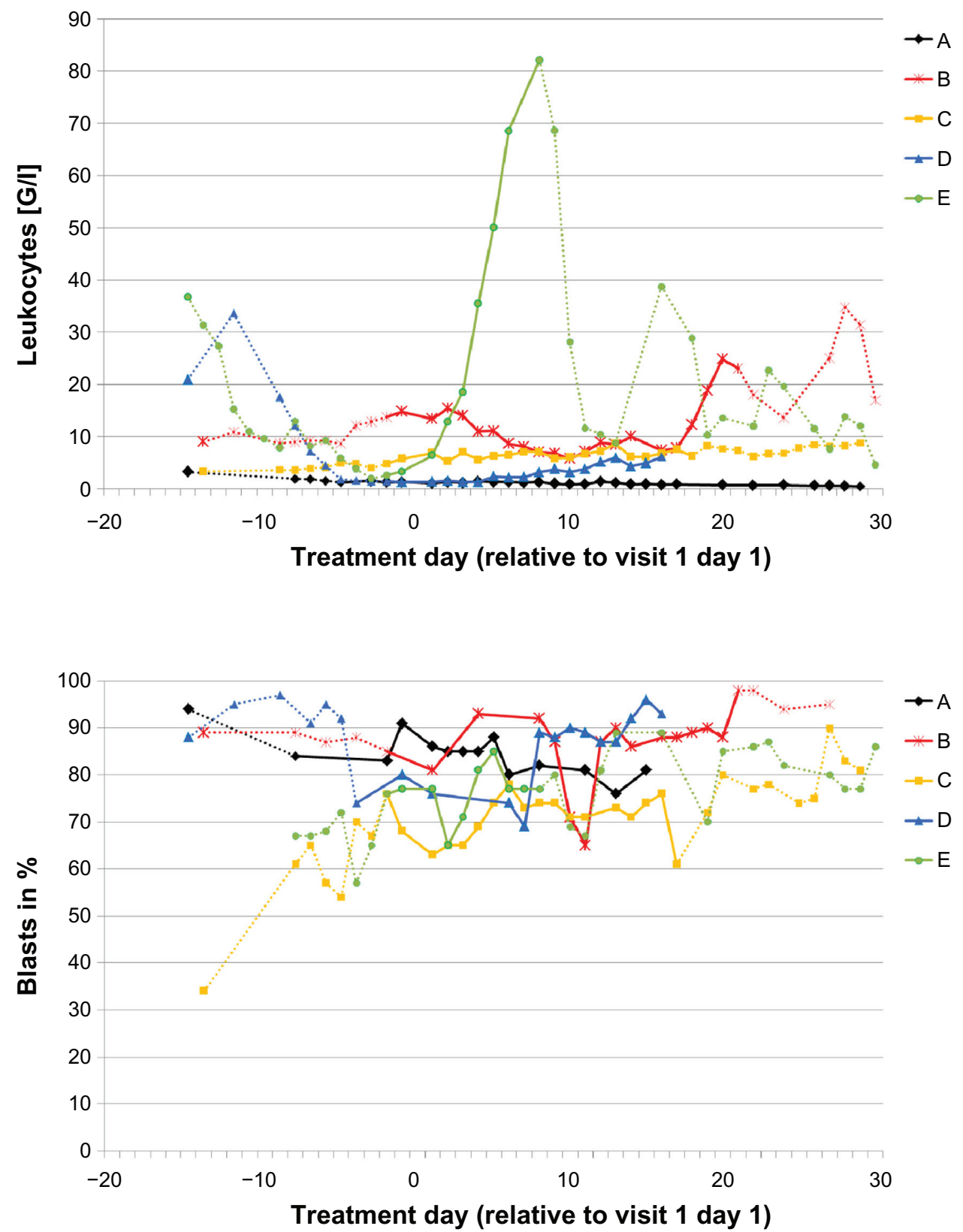

Figure 2 Daily leukocyte and blast cell count leukocyte (upper panel) and blast cell count (lower panel) for patients A-E are displayed in relationship to the single dose and multiple doses of LY2457546. Solid lines indicate dosing period with LY2457546, while dotted lines indicate time periods without LY2457546 treatment.

observed a significant but transient decrease in leukocyte and blast cell counts through day 10 (Figures $2 \mathrm{~A}$ and $2 \mathrm{~B}$ ).

The most frequently observed adverse events in this study were headache, epistaxis, petechiae, and hypokalemia ( $n=3$ each, see Table 3). All these adverse events were graded as CTCAE 1 or 2, and were considered to be related to the disease rather than the study drug. Grade 3 adverse events included two cases of febrile neutropenia, hypotension, and infection-related adverse events, including anal abscess, pneumonia, catheter-related infection, fungal sepsis, neutropenic sepsis, and breast cellulitis (Table 3).
As expected for this patient population, bone marrow was already depressed at study entry. A transient Grade 4 hypophosphatemia was observed and corrected with calcium phosphate infusions. A Grade 4 hemorrhage was considered to be related to disease progression. All recorded Grade 3 and 4 adverse events were not considered to be related to the study drug, with the exception of a Grade 3 generalized muscle weakness in patient $\mathrm{C}$, who developed this adverse event 14 days after starting LY2457546 administration, and the adverse event resolved within seven days of stopping LY2457546. Because of its likely association with 
Table 3 Overview of all adverse events* regardless of causality ( $\mathrm{n}=5$ patients)

\begin{tabular}{|c|c|c|c|c|}
\hline & & m & rade & \\
\hline \multicolumn{5}{|l|}{ System organ class } \\
\hline Preferred term & I & 2 & 3 & 4 \\
\hline \multicolumn{5}{|c|}{ Blood and lymphatic system disorders } \\
\hline Febrile neutropenia & & & 2 & \\
\hline Splenomegaly & I & & & \\
\hline \multicolumn{5}{|l|}{ Ear and labyrinthine disorders } \\
\hline Vertigo & 1 & & & \\
\hline \multicolumn{5}{|l|}{ Eye disorders } \\
\hline Keratoconjunctivitis sicca & & 1 & & \\
\hline \multicolumn{5}{|l|}{ Gastrointestinal disorders } \\
\hline Chapped lips & I & & & \\
\hline Ulcerative colitis & I & & & \\
\hline Constipation & 1 & I & & \\
\hline Diarrhea & 2 & & & \\
\hline Gingival hyperplasia & & I & & \\
\hline Hemorrhoids & 1 & 1 & & \\
\hline Inguinal hernia & 1 & & & \\
\hline Nausea & 1 & & & \\
\hline Stomatitis & & 1 & & \\
\hline \multicolumn{5}{|c|}{ General disorders and administration site conditions } \\
\hline Asthenia (muscle weakness) & & & I & \\
\hline Fatigue & 1 & & & \\
\hline Peripheral edema & 1 & & & \\
\hline \multicolumn{5}{|l|}{ Hepatobiliary disorders } \\
\hline Hepatomegaly & 1 & & & \\
\hline \multicolumn{5}{|l|}{ Infections } \\
\hline Anal abscess & & & I & \\
\hline Breast cellulitis & & & I & \\
\hline Catheter-related infection & & & 1 & \\
\hline Fungal sepsis & & & 1 & \\
\hline Neutropenic sepsis & & & 1 & \\
\hline \multicolumn{5}{|l|}{ Pneumonia } \\
\hline \multicolumn{5}{|c|}{ Metabolism and nutrition disorders } \\
\hline Hypokalemia & 3 & & & \\
\hline \multicolumn{4}{|l|}{ Hypophosphatemia } & I \\
\hline \multicolumn{4}{|c|}{ Musculoskeletal and connective tissue disorders } & \\
\hline Back pain & & I & & \\
\hline Musculoskeletal pain & 1 & & & \\
\hline Osteoporosis & 1 & & & \\
\hline \multicolumn{5}{|c|}{ Neoplasms (benign, malignant, and unspecified) } \\
\hline Hemangioma of liver & 1 & & & \\
\hline \multicolumn{5}{|l|}{ Nervous system disorders } \\
\hline Headache & 3 & & & \\
\hline \multicolumn{5}{|l|}{ Psychiatric disorders } \\
\hline Anxiety & & 2 & & \\
\hline Insomnia & & I & & \\
\hline \multicolumn{5}{|l|}{ Renal and urinary disorders } \\
\hline Bladder spasm & & I & & \\
\hline Hematuria & I & & & \\
\hline Nephrolithiasis & I & & & \\
\hline \multicolumn{5}{|c|}{ Respiratory, thoracic and mediastinal disorders } \\
\hline Asthma & & I & & \\
\hline Cough & I & & & \\
\hline Epistaxis & I & 2 & & \\
\hline Oropharyngeal pain & I & & & \\
\hline
\end{tabular}

Table 3 (Continued)

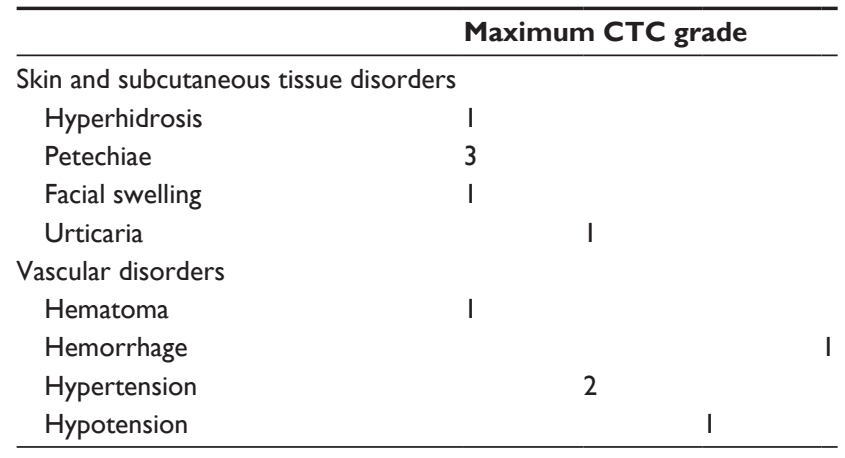

Note: *Adverse events are included in this table starting from first dose of LY2457546.

Abbreviation: CTC, Common Toxicity Criteria.

LY2457546, and after excluding other potential medical or drug-related causes, this toxicity was deemed to be a dose-limiting toxicity for this cohort.

Because other multikinase inhibitors have dose-dependent adverse effects on cardiac conductivity, ${ }^{47}$ cardiac monitoring with a detailed QTc risk assessment was implemented in this study. ${ }^{48}$ In three patients abnormal electrocardiograms were present at study entry, which were not deemed medically significant. QTc prolongation after Bazet and Fridericia corrections were not present after the single-dose administration (Figure 3). Compared with baseline, the QTc prolongation remained unchanged over the 48-hour follow-up period following single-dose administration. For the multipledose treatment, increased QTc prolongation was observed only for patient $\mathrm{D}$ after eight days of treatment. A relationship with the study drug appears unlikely, because the exposure of patient D to LY2457546 was lower than in other patients during the multiple-dose study period (Figure 3 ). In addition, patient $\mathrm{D}$ also suffered from goiter and showed a steep decline in T3, T4, and TSH in parallel with QTc prolongation, strongly suggesting that thyroid function influenced the QTc interval (data not shown).

An unexpected pharmacokinetic profile was observed in all five patients, which was substantially different from the animal pharmacokinetic studies (data on file, Eli Lilly and Company, Figures 3 and 4). Extensive accumulation of plasma LY2457546 was observed, and the compound did not appear to enter an elimination phase, as assessed by pharmacokinetic day profiles following single (visit 0 ) and multiple oral doses (visits 1 and 2, Figures 4A, 4B, and 4C). As a result of this observation and the intraindividual variability of LY2457546, no terminal elimination half-life could be defined for any of the patients. Hence, the only reported parameters are $\mathrm{C}_{\max }, \mathrm{T}_{\max }, \mathrm{C}_{\text {last }}$, and $\mathrm{t}_{\text {last }}$, and the only calcu- 

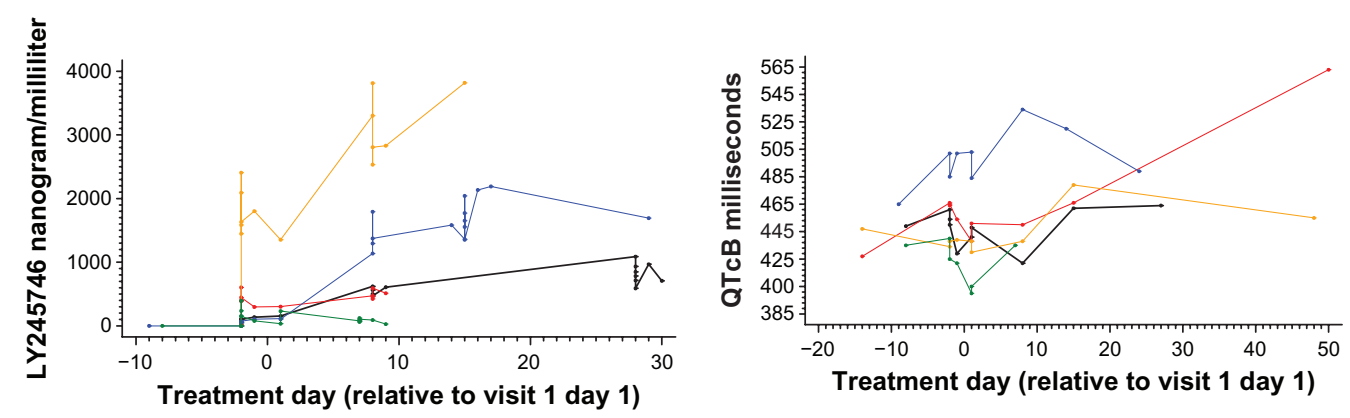

\begin{tabular}{|c|c|c|c|}
\hline Assessment & Statistics & QTcB & QTcF \\
\hline \multicolumn{4}{|l|}{ Single dose } \\
\hline \multirow[t]{3}{*}{ Predose $^{\mathrm{a}}$} & Median (Range) & $458(434-502)$ & $435.6(406.7-482.9)$ \\
\hline & Total number of patients & 5 & 5 \\
\hline & Number of observations & 8 & 24 \\
\hline \multirow[t]{3}{*}{ Postdose ${ }^{b}$} & Median (Range) & $439(422-502)$ & $434.3(394.0-477.8)$ \\
\hline & Total number of patients & 5 & 5 \\
\hline & Number of observations & 5 & 20 \\
\hline \multicolumn{4}{|l|}{ Multiple dose } \\
\hline \multirow{3}{*}{ Predose $^{c}$} & Median (Range) & $438(400-503)$ & $431.5(385.3-481.1)$ \\
\hline & Total number of patients & 5 & 5 \\
\hline & Number of observations & 5 & 15 \\
\hline \multirow[t]{3}{*}{ Postdose $^{d}$} & Median (Range) & $451(405-534)$ & $439.25(388.6-513.1)$ \\
\hline & Total number of patients & 5 & 5 \\
\hline & Number of observations & 15 & 44 \\
\hline
\end{tabular}

Patient number $\rightarrow A \quad B \quad \cdots C \quad \cdots D \quad \cdots B$

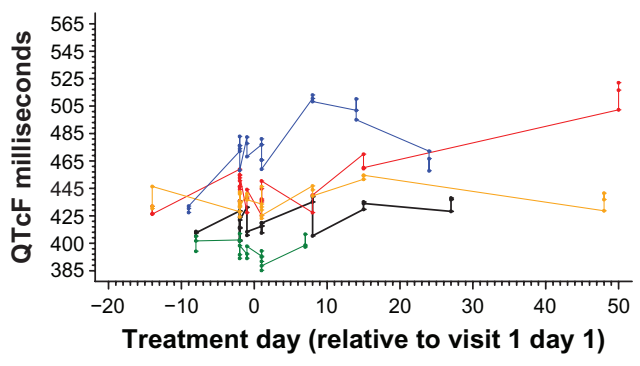

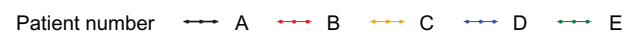

Figure 3 QTc assessment in relationship to plasma concentration of LY2457546. Time course of LY2457546 plasma concentrations for patients A-E (panel A). QTcB (panel B) and QTcF (panel C) are displayed in relationship to the single dose and multiple doses of LY2457546. A summary table of changes in QTcF and QTcB shows no changes in QTc compared with plasma LY2457546 concentration.

Abbreviations: QTcF, Fridericia's corrected QTc; QTcB, Bazet's corrected QTc.

A

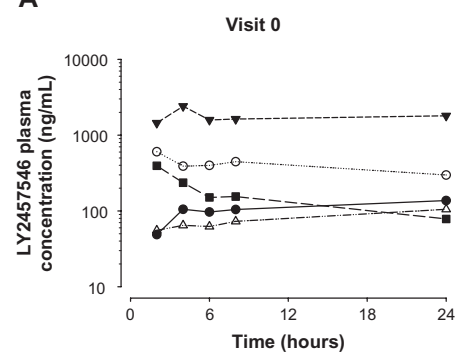

B

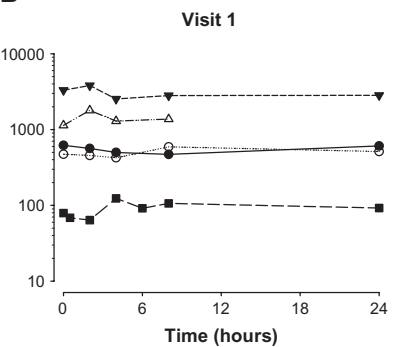

C

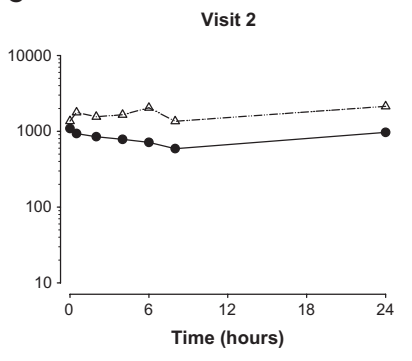

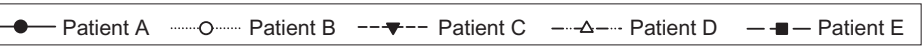

。

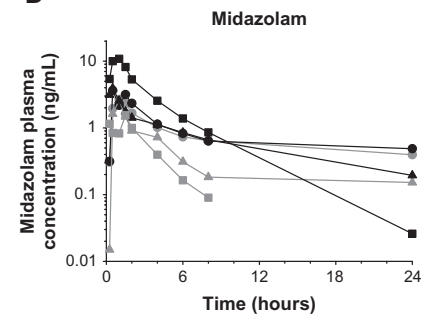

E

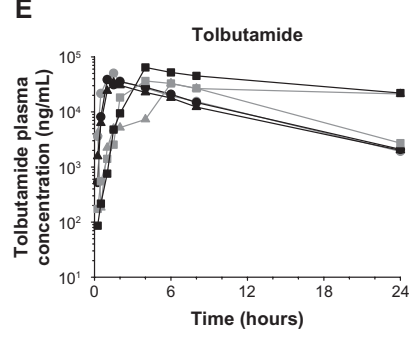

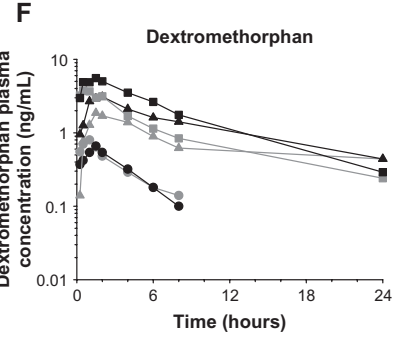

$\longrightarrow$ Patient $A$, before $L Y \leadsto$ Patient $D$, before $L Y \quad \longrightarrow$ Patient $E$, before $L Y$ $\multimap$ Patient $A$, after LY $\longrightarrow$ Patient $D$, after $L Y \quad \rightarrow$ Patient $E$, after $L Y$

Figure 4 Pharmacokinetic profile of LY2457546 and the drug-drug interaction cocktail compounds (midazolam/tolbutamide/dextromethorphan) with and without LY2457546. Individual LY2457546 plasma concentration versus time profiles following a single dose (visit 0, panel A) and multiple oral doses of 50 mg (visit I, panel B; visit 2, panel C). Midazolam (panel D), tolbutamide (panel E), and dextromethorphan (panel F) plasma concentration to time profiles following cocktail of $0.2 \mathrm{mg}$ midazolam, $500 \mathrm{mg}$ tolbutamide, and $30 \mathrm{mg}$ dextromethorphan, respectively, before and after treatment with LY2457546.

Abbreviation: LY, LY2457546. 
Table 4 Pharmacokinetic parameters following single and multiple oral doses of LY2457546 $50 \mathrm{mg}$

\begin{tabular}{|c|c|c|c|c|c|c|}
\hline Subject & $T_{\max }(\mathbf{h})$ & $C_{\max }(n g / m L)$ & $\mathbf{T}_{\text {last }}(\mathbf{h})$ & $C_{\text {last }}(\mathrm{ng} / \mathrm{mL})$ & $A \cup C_{\text {last }}(h * n g / m L)$ & AUC0_24 (h*ng/mL) \\
\hline \multicolumn{7}{|l|}{ Visit 0} \\
\hline A & 48 & 154.876 & 48 & 154.876 & 6030 & 2520 \\
\hline B & 2 & 604.581 & 48 & 302.003 & 16100 & 8930 \\
\hline C & 4 & 2406.55 & 48 & 1354.06 & 79200 & 41500 \\
\hline D & 24 & 105.113 & 24 & 105.113 & 1850 & 1850 \\
\hline$E$ & 2 & 394.238 & 24 & 78.459 & 3420 & 3420 \\
\hline $\mathrm{N}$ & 5 & 5 & 5 & 5 & 5 & 5 \\
\hline Min & 2 & 105.113 & 24 & 78.459 & 1850 & 1850 \\
\hline Max & 48 & 2406.55 & 48 & 1354.06 & 79200 & 41500 \\
\hline \multicolumn{7}{|l|}{ Visit I } \\
\hline A & 0 & 619.909 & 24 & 607.429 & 12800 & 12800 \\
\hline B & 8 & 591.772 & 24 & 513.075 & 12700 & 12700 \\
\hline C & 2 & 3812.913 & 24 & 2830.537 & 69200 & 69100 \\
\hline D & 2 & 1792.419 & 8 & $|373.02|$ & 11300 & $\mathrm{nc}$ \\
\hline $\mathrm{E}$ & 4 & 123.44 & 48 & 28.097 & 3610 & 2320 \\
\hline $\mathrm{N}$ & 5 & 5 & 5 & 5 & 5 & 3 \\
\hline Min & 0 & 123.44 & 8 & 28.097 & 3610 & 2320 \\
\hline Max & 8 & 3812.913 & 48 & 2830.537 & 69200 & 69100 \\
\hline \multicolumn{7}{|l|}{ Visit 2} \\
\hline A & 0 & 1087.972 & 48 & 708.777 & 38400 & 18500 \\
\hline D & 48 & 2190.006 & 48 & 2190.006 & 93400 & 41500 \\
\hline $\mathrm{N}$ & 2 & 2 & 2 & 2 & 2 & 2 \\
\hline Min & 0 & 1087.972 & 48 & 708.777 & 38400 & 18500 \\
\hline Max & 48 & 2190.006 & 48 & 2190.006 & 93400 & 41500 \\
\hline
\end{tabular}

Abbreviations: $T_{\max }$, time to maximum concentration; $C_{\max }$, maximum plasma concentration; $T_{\text {last }}$, last time to maximum concentration; $C_{\text {lass }}$, last plasma concentration; $\mathrm{AUC}_{\text {last }}$ last area under the plasma concentration versus time curve; min, minimum; max, maximum.

lated parameter was $\mathrm{AUC}_{0-24}$ (Table 4). Furthermore, plasma LY2457546 exposures were much higher than expected.

No consistent drug-drug interactions with midazolam, tolbutamide, and dextromethorphan were observed (Figures 4D, 4E and 4F), suggesting that any interference with CYP3A4, CYPP2D6, or CYP2C9 was minimal or not present. This was consistent with the previous in vitro drug-drug interaction studies (data on file, Eli Lilly and Company).

In previous studies of multikinase inhibitors in AML, Western blotting was used to determine the pharmacodynamic effects of sunitinib. ${ }^{32}$ Here, we used a novel and validated quantitative flow cytometry-based assay to evaluate changes in phosphoprotein expression in AML blasts. Although we observed some variability in the makeup of the leukemia cell population, all five patients had CD34+ blasts, and three of the five patients had the $\mathrm{CD} 34^{+} \mathrm{CD} 11 \mathrm{~b}^{-}$ expression phenotype (Figure 5). Based on this expression of CD34 and CD11b, we defined four subgroups, which were evaluated for phosphoprotein expression. In all five patients, baseline expression of pFLT3, pcKIT, pS6, and pY100 was observed, especially in the $\mathrm{CD} 34^{+} \mathrm{CD} 11 \mathrm{~b}^{-}$cells. However,
pAKT, pERK, and pSTAT were not expressed (Supplemental Figure S1). Clear separation from the isotype controls was found for pFLT3, pcKIT, pS6, and pY100. As exemplified by the pFLT3 expression, all patients (except patient E) had a similar range of pFLT3 expression (Supplemental Figure S2). Compared with pretreatment phosphoprotein expression, we detected a downregulation of median phosphoprotein expression for pFLT3, pcKIT, and pS6 in most of the patients (Figure 6 and Supplemental Figure S3). Following single-dose administration, pFLT3, pcKIT, and pS6 expression was reduced at four hours after administration of LY2457546 in three of the five patients (patients A, C, and E, Supplemental Figure S3). After multiple dosing of LY2457546, we observed reduced expression of pFLT3 and pcKIT in at least three patients $(\mathrm{B}, \mathrm{C}$, and $\mathrm{E})$, and a similar trend was observed for pS6 in another three patients (patients A, B, and E, Figure 6 and Supplemental Figure S4). Interestingly, phosphoprotein expression increased in all patients at the time of progression or after treatment with LY2457546 had ended, and responded briefly to retreatment with hydroxyurea (patients B, C, and E, Figure 6, Supplemental Figure S4). 


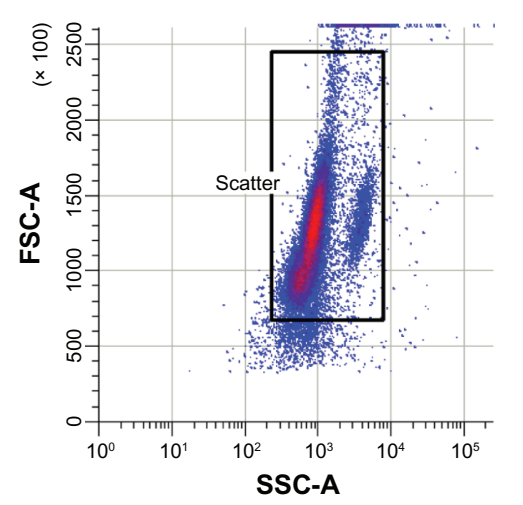

Patient A

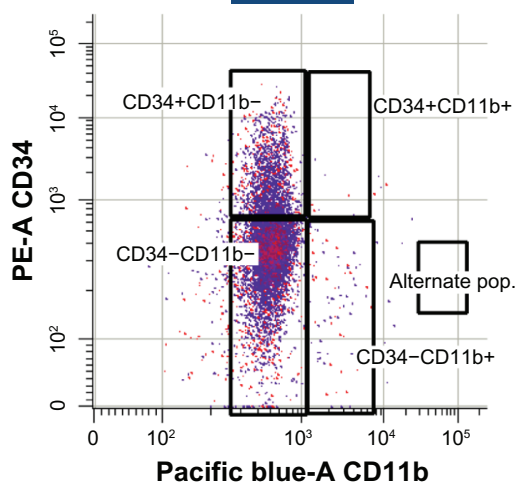

Patient C

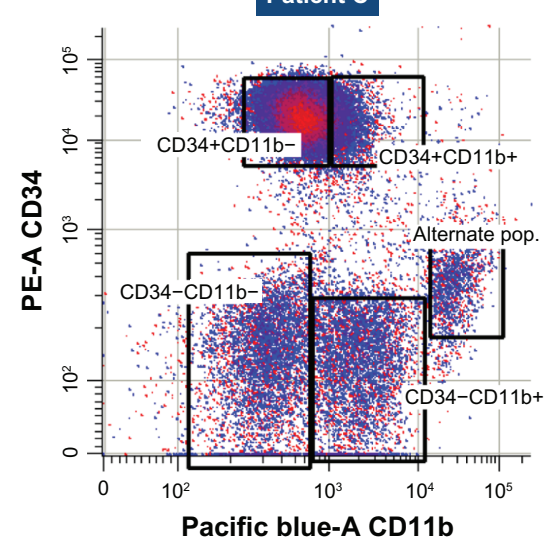

Patient D

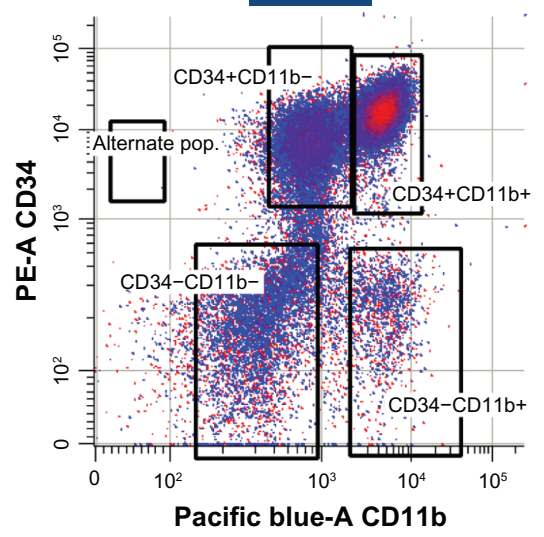

Patient B

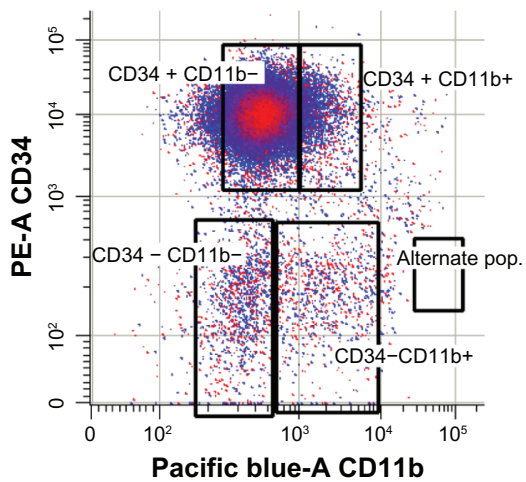

Patient E

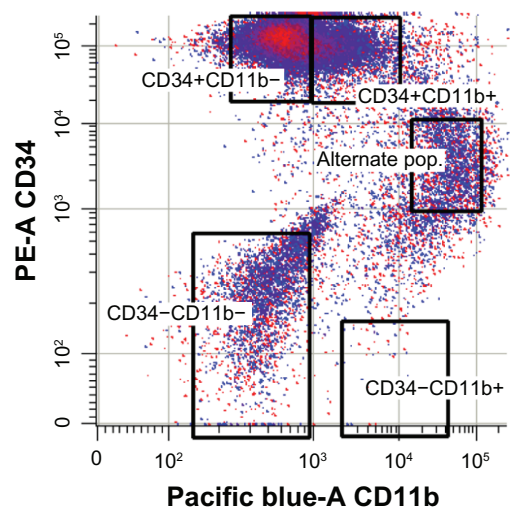

Figure 5 Flow cytometric assessment of blast cells. All blast cells were gated based on forward versus side scatter (left upper panel), and assessed for CD34 and CDI Ib expression. Individual patients (A-E) are shown after adjusting for appropriate gating for CD34 and CDIIb expression, establishing four different expression patterns,

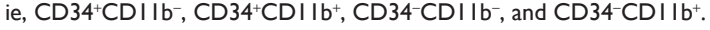

\section{Discussion}

In the present study, we evaluated the safety and biological activity of LY2457546 in patients with relapsed AML. Due to an unfavorable pharmacokinetic profile for LY2457546, the study was terminated early without establishing a biologically effective dose range. When considering the conduct of a first-in-human dose study in patients with relapsed AML, it is necessary to balance the need to evaluate safety with the need to treat a rapidly progressing malignancy. Therefore, new molecular entities with an acceptable preclinical safety profile and antileukemic activity in animal models are considered acceptable candidates for first-in-human dose trials in relapsed AML patients.

In preclinical toxicology studies, LY2457546 had toxicities similar to those reported in nonclinical studies of other multikinase inhibitors, including reversible bone marrow toxicity, minimal liver inflammation, reversible physeal dysplasia (a common finding for antiangiogenic agents in rats and dogs), ${ }^{49}$ reversible lymphoid necrosis of Peyer's patches, and skin depigmentation or whitening of the hair consistent with the previously described effects of c-KIT inhibitors. ${ }^{50}$ Overall, the preclinical safety profile indicated that LY2457546 had a favorable toxicity profile compared with other multikinase inhibitors. ${ }^{51}$

In addition to this favorable preclinical toxicity profile, the preclinical efficacy models with MV4-11 cells containing the FLT3-ITD mutation suggested that LY2457546 was 10-fold more potent than sunitinib in controlling leukemia growth in animals. ${ }^{52}$ Based on these combined preclinical safety, efficacy, and other published inhibition profiles of similar multikinase inhibitors, a predictive pharmacokinetic/ pharmacodynamic model defined $50 \mathrm{mg}$ per day as a starting dose which had the potential to provide an antileukemia effect in patients. ${ }^{38,53,54}$

Unfortunately, the pharmacokinetic profile of LY2457546 in AML patients showed unexpected variability, and differed substantially from the preclinical pharmacokinetic data. Hence, the pharmacokinetic/pharmacodynamic model could not be leveraged for the first-in-human dose study. 

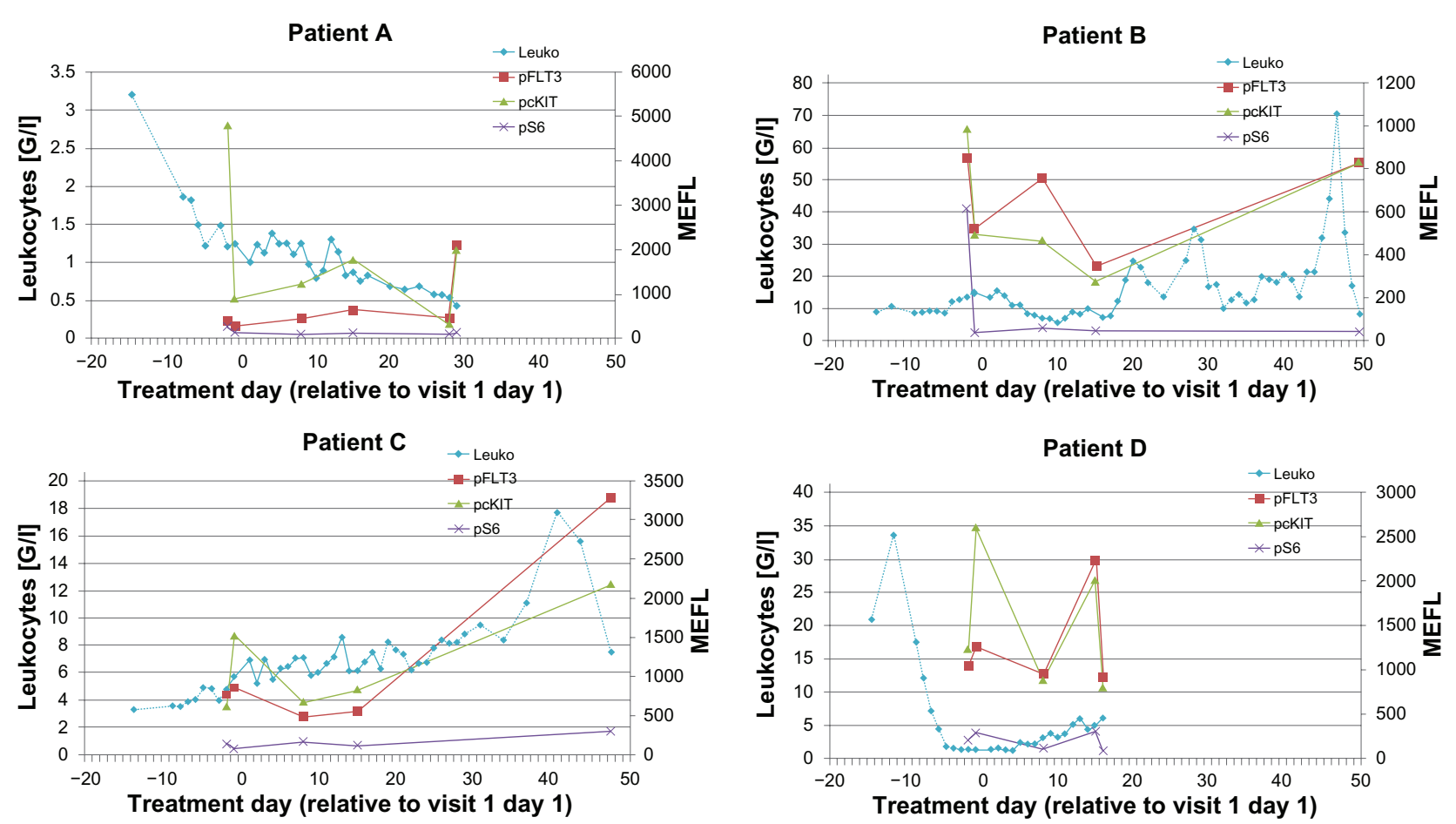

Patient E

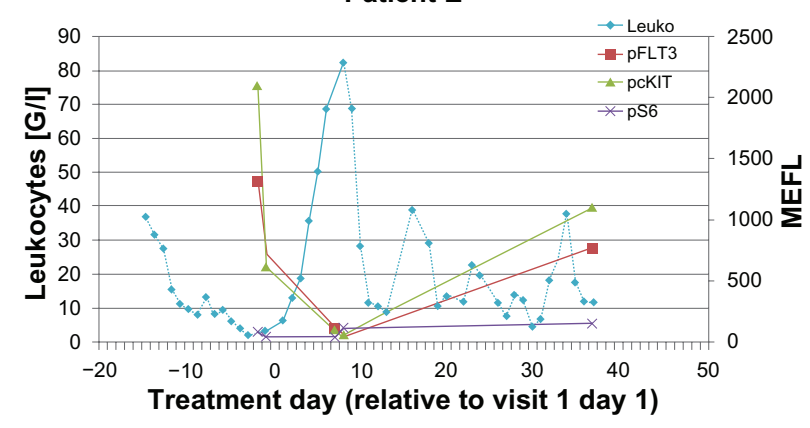

Figure 6 Flow cytometric assessment of pFLT3, pcKIT, and pS6 in peripheral CD34+CDII- blood cells for patients (A-E) before and after LY2457546 administration. Expression of pFLT3, pcKIT, and pS6 at predose, day I, day 8, day 15, and at the end of the study was measured in peripheral CD $34^{+} \mathrm{CDII-}$ blood cells by fluorescence activated cell sorting. Expression of phosphoproteins as detected by MEFL for individual patients (A-E) is shown in relationship to leukocyte counts. Solid lines of leukocyte counts indicate dosing period with LY2457546, and dotted lines of leukocyte counts indicate time periods without LY2457546 treatment.

Abbreviation: MEFL, molecules of equivalent fluorescence.

Variable pharmacokinetic profiles have also been reported for other multikinase inhibitors, such as sorafenib and sunitinib. ${ }^{55,56}$ In the case of LY2457546, the plasma pharmacokinetics suggest an accumulation likely due to a lack of elimination or to absorption issues. Such a pharmacokinetic profile is not observed for sorafenib and sunitinib. The cause for the unexpected pharmacokinetic profile of LY2457546 was not identified in this study. Protein binding may have influenced the pharmacokinetic profile of LY2457546. All AML patients in this study had a low total albumin, which raises the possibility that the unbound fraction of LY2457546 was larger than expected. However, no formal protein-binding study was conducted, and thus it was not possible to determine the influence of protein-binding on the pharmacokinetic profile of LY2457546. Like other multikinase inhibitors, such as imatinib and sunitinib, drugs altering the $\mathrm{P} 450$ pathway could have affected the pharmacokinetic profile of LY2457546. ${ }^{57,58}$ While in vitro or in vivo experiments with LY2457546 suggested the lack of such an interference (data on file, Eli Lilly and Company), animal models cannot definitively exclude such a risk in patients. ${ }^{59-63}$ Hence, a drug-drug interaction assessment was conducted starting with the first cohort. A drug-drug interaction risk was not observed, as demonstrated by the unchanged plasma pharmacokinetics of P450 pathway enzyme substrates, ie, midazolam, tolbutamide, and dextromethorphan (Figure 4). In the future, five-drug cocktail studies may provide a more comprehensive assessment of how hepatic metabolism may 
affect the pharmacokinetics of multikinase inhibitors. ${ }^{43}$ Also, tolbutamide and midazolam are increasingly difficult to obtain for drug-drug interaction studies, because their pharmaceutical use is in decline or restricted in most European Union countries. Another factor influencing the pharmacokinetic profile of LY2457546 is stomach acidity, which may have affected the absorption of LY2457546. ${ }^{64}$ For instance, four of our five patients were taking a proton pump inhibitor (pantoprazole), which may have altered the pharmacokinetics of LY2457546. Further, enterohepatic recycling of LY2457546 may also explain the unexpected pharmacokinetic profile. In both instances, a change in formulation of LY2457546 may help to address the observed unfavorable pharmacokinetic profile.

Despite this pharmacokinetic profile, there was little or no drug-associated QTc prolongation. Some central health authorities have expressed the concern that QTc studies are not adequately conducted in oncology trials. ${ }^{65}$ However, evaluating the risk of QTc prolongation in cancer patients is not straightforward. When the pharmacokinetic profile is not known in a first-in-human dose trial, the assessment of QTc risk is further complicated by the overall condition of the study population, consisting of terminally ill patients with heavily pretreated conditions receiving several comedications and suffering from coexisting disease. Most patients in our study had previously received multiple cycles of anthracycline-based chemotherapy as part of their induction/consolidation treatment. Other potentially cardiotoxic comedications having a definite association with QTc prolongation ${ }^{66}$ such as amitriptyline, diphenhydramine, pantoprazole, fluconazole, ketoconazole, azithromycin, and ciprofloxacin, were identified in this study, but were not associated with QTc prolongation. Pre-existing medical conditions of patients in this study were more likely to interfere with electrocardiographic interpretation, ie, arterial hypertension Grade 2 (patient C), goiter (patient D), and asthma (patient E). QTc studies are generally conducted in healthy volunteers after the pharmacokinetic profile of an agent is well established ${ }^{47}$ However, recent requests from competent health authorities to investigate QTc as part of oncology firstin-human dose studies may be more motivated by concerns about the conductivity risk for specific drug classes (as in this case, where LY2457546 was classified as belonging to the multikinase inhibitor class, which also includes sunitinib and sorafenib). In contrast with other approved multikinase inhibitors, LY2457546 did not show significant electrophysiological toxicity in animals. While the potential risk of QTc prolongation was raised when LY2457546 was found to inhibit the human ether-à-go-go-related gene (hERG) at an
$\mathrm{IC}_{50}$ of $0.2 \mu \mathrm{M}$, no QTc interval prolongation was observed in electrocardiograms after single or repeat doses in dogs at maximal plasma concentrations of up to $7 \mu \mathrm{g} / \mathrm{mL}$ (data on file, Eli Lilly and Company). Hence, it was reassuring that we only observed QTc prolongation in a patient with goiter (patient D) which was not associated with high LY2457546 concentration (Figure 3).

The Grade 3 muscle weakness in one patient was reminiscent of a similar toxicity in AML patients observed with MS-275, a histone deacetylase inhibitor. ${ }^{67}$ MS-275 was associated with Grade 4 neurologic toxicity, consisting of somnolence, weakness, and unsteady gait, and associated with Grade 3 laboratory abnormalities, including elevated lactate dehydrogenase, hypertriglyceridemia, and hyperglycemia ${ }^{67}$ Also, in AML studies with MLN518/tandutinib, three cases of tandutinib-related muscular weakness were reported as dose-limiting toxicities. ${ }^{27}$ Based on a recent review of several FLT3 inhibitors, muscle weakness toxicity is considered an exception among other FLT3 inhibitors. The neurotoxicities observed with MS-275 and MLN518 are perhaps due to the broad inhibition profile of such type of inhibitors, which may include inhibition of the muscle-type nicotinic receptor. ${ }^{68}$ For LY2457546, no such inhibition of a muscle-type nicotinic receptor has been evaluated.

Finally, we measured the pharmacodynamic effects of LY2457546 by assessing changes of phosphoproteins in blast cells using quantitative flow cytometry ${ }^{69}$ and not Western blotting. ${ }^{32}$ Western blotting was used in studies with sunitinib, where a reduction of pFLT3 was reported in $77 \%$ patients (10/13) at $200 \mathrm{mg}$, while lower doses showed a pFLT3 reduction in $25 \%$ of the patients $(2 / 8)$. Western blotting was also used to detect a reduction in pFLT3 expression after $300 \mathrm{mg}$ and $525 \mathrm{mg}$ twice-daily dosing with MLN518/ tandutinib. ${ }^{27}$ In contrast with Western blotting, the recent progress in flow cytometry allows a quantitative assessment of basal expression of phosphoproteins ${ }^{70}$ and treatmentassociated monitoring of signaling pathways. ${ }^{45,71}$ Based on the predictive pharmacokinetic/pharmacodynamic model, we expected an inhibition of most phosphoprotein kinases at the $50 \mathrm{mg} /$ day dose. In fact, the flow cytometry studies showed an inhibition for pFLT3, pcKIT, and pS6 in three of our five patients. Surprisingly, pAKT and pERK expression was absent in all patients. This failure of detecting pAKT and pERK might be due to either a loss of expression during sample shipment or the lack of expression in patients with advanced AML. While we achieved reductions in pFLT3 levels after LY2457546 administration, the reduction was not associated with a durable reduction in blast cell counts. 
It is possible that flow cytometry is a more sensitive assay compared with Western blotting, and thus the $50 \mathrm{mg} /$ day dose of LY2457546 was a threshold dose above which antileukemic responses may have occurred as predicted by the pharmacokinetic/pharmacodynamic model. Unfortunately, we were not able to evaluate the possibility of a dose-dependent increase in phosphoprotein inhibition and its associated antileukemic effect in this study. Nevertheless, the approach of using multiparametric flow cytometry is encouraging, and should be further evaluated in clinical trials with similar agents.

Overall, this first-in-human dose study provides a detailed approach on how to integrate the evaluation of safety (including concentration-associated QTc assessments as part of the definition of dose-limiting toxicity), pharmacokinetics and pharmacodynamics of a multikinase inhibitor in AML patients.

\section{Acknowledgments}

We would like to thank the following contributors to this study: Joanna Burke, Ute Ohnmacht, David Snyder, Tommy Luk, and the Omnicare clinical development team. We would like to thank the Department of Hematology at the University of Bologna, Italy, Professor Gridelli, and Professor Schlenk and his team at the University of Ulm, Germany, for their contributions to this research.

\section{Disclosure}

ML, GD, GD, VA, TPB, and KKA are employed by and hold stocks in Eli Lilly and Company, which owns LY2457546. This study was sponsored by Eli Lilly and Company.

\section{References}

1. Estey E, Dohner H. Acute myeloid leukaemia. Lancet. 2006;368(9550): 1894-1907.

2. Tallman MS, Gilliland DG, Rowe JM. Drug therapy for acute myeloid leukemia. Blood. 2005;106(4):1154-1163.

3. Schlenk RF, Dohner K, Krauter J, et al. Mutations and treatment outcome in cytogenetically normal acute myeloid leukemia. $N$ Engl J Med. 2008;358(18):1909-1918.

4. Traxler P, Bold G, Buchdunger E, et al. Tyrosine kinase inhibitors: From rational design to clinical trials. Med Res Rev. 2001;21(6):499-512.

5. Wahlin A, Markevarn B, Golovleva I, Nilsson M. Prognostic significance of risk group stratification in elderly patients with acute myeloid leukaemia. Br J Haematol. 2001;115(1):25-33.

6. Arbiser JL, Govindarajan B, Bai X, et al. Functional tyrosine kinase inhibitor profiling: A generally applicable method points to a novel role of platelet-derived growth factor receptor-beta in tuberous sclerosis. $\mathrm{Am} \mathrm{J}$ Pathol. 2002;161(3):781-786.

7. Byrd JC, Mrozek K, Dodge RK, et al. Pretreatment cytogenetic abnormalities are predictive of induction success, cumulative incidence of relapse, and overall survival in adult patients with de novo acute myeloid leukemia: Results from Cancer and Leukemia Group B (CALGB 8461). Blood. 2002;100(13):4325-4336.
8. Preudhomme C, Sagot C, Boissel N, et al. Favorable prognostic significance of CEBPA mutations in patients with de novo acute myeloid leukemia: A study from the Acute Leukemia French Association (ALFA). Blood. 2002;100(8):2717-2723.

9. Andersson A, Johansson B, Lassen C, Mitelman F, Billstrom R, Fioretos T. Clinical impact of internal tandem duplications and activating point mutations in FLT3 in acute myeloid leukemia in elderly patients. Eur J Haematol. 2004;72(5):307-313.

10. Bullinger L, Dohner K, Bair E, et al. Use of gene-expression profiling to identify prognostic subclasses in adult acute myeloid leukemia. $N$ Engl $J$ Med. 2004;350(16):1605-1616.

11. Dohner K, Schlenk RF, Habdank M, et al. Mutant nucleophosmin (NPM1) predicts favorable prognosis in younger adults with acute myeloid leukemia and normal cytogenetics: Interaction with other gene mutations. Blood. 2005;106(12):3740-3746.

12. Stone RM, DeAngelo DJ, Klimek V, et al. Patients with acute myeloid leukemia and an activating mutation in FLT3 respond to a small-molecule FLT3 tyrosine kinase inhibitor, PKC412. Blood. 2005;105(1):54-60.

13. Verhaak RGW, Goudswaard CS, van Putten W, et al. Mutations in nucleophosmin (NPM1) in acute myeloid leukemia (AML): Association with other gene abnormalities and previously established gene expression signatures and their favorable prognostic significance. Blood. 2005; 106:3747-3754.

14. Bullinger L, Dohner K, Kranz R, et al. An FLT3 gene-expression signature predicts clinical outcome in normal karyotype AML. Blood. 2008;111(9):4490-4495.

15. Kornblau SM, Tibes R, Qiu YH, et al. Functional proteomic profiling of AML predicts response and survival. Blood. 2009;113(1):154-164.

16. Fielder W, Graeven U, Ergun S, et al. Expression of FLT4 and its ligand VEGF-C in acute myeloid leukemia. Leukemia. 1997;11(8): 1234-1237.

17. Shawver LK, Schwartz DP, Mann E, et al. Inhibition of plateletderived growth factor-mediated signal transduction and tumor growth by N-[4-(trifluoromethyl)-phenyl]5-methylisoxazole-4-carboxamide. Clin Cancer Res. 1997;3(7):1167-1177.

18. Dias S, Hattori K, Heissig B, et al. Inhibition of both paracrine and autocrine VEGF/VEGFR-2 signaling pathways is essential to induce long-term remission of xenotransplanted human leukemias. Proc Natl Acad Sci U SA. 2001;98(19):10857-10862.

19. Dias S, Shmelkov SV, Lam G, Rafii S. VEGF(165) promotes survival of leukemic cells by Hsp90-mediated induction of Bcl-2 expression and apoptosis inhibition. Blood. 2002;99(7):2532-2540.

20. Moehler TM, Hillengass J, Goldschmidt H, Ho AD. Antiangiogenic therapy in hematologic malignancies. Curr Pharm Des. 2004;10(11): $1221-1234$

21. Santos SC, Dias S. Internal and external autocrine VEGF/KDR loops regulate survival of subsets of acute leukemia through distinct signaling pathways. Blood. 2004;103(10):3883-3889.

22. Kessler T, Fehrmann F, Bieker R, Berdel WE, Mesters RM. Vascular endothelial growth factor and its receptor as drug targets in hematological malignancies. Curr Drug Targets. 2007;8(2):257-268.

23. Gossage L, Eisen T. Targeting multiple kinase pathways: A change in paradigm. Clin Cancer Res. 2010;16(7):1973-1978.

24. Stone RM. Novel therapeutic agents in acute myeloid leukemia. Exp Hematol. 2007;35(4 Suppl 1):163-166.

25. Fiedler W, Serve H, Dohner H, et al. A phase 1 study of SU11248 in the treatment of patients with refractory or resistant acute myeloid leukemia (AML) or not amenable to conventional therapy for the disease. Blood. 2005;105(3):986-993.

26. Stover EH, Chen J, Lee BH, et al. The small molecule tyrosine kinase inhibitor AMN107 inhibits TEL-PDGFRbeta and FIP1 L1-PDGF Ralpha in vitro and in vivo. Blood. 2005;106(9):3206-3213.

27. DeAngelo DJ, Stone RM, Heaney ML, et al. Phase 1 clinical results with tandutinib (MLN518), a novel FLT3 antagonist, in patients with acute myelogenous leukemia or high-risk myelodysplastic syndrome: Safety, pharmacokinetics, and pharmacodynamics. Blood. 2006;108(12):3674-3681. 
28. Knapper S, Burnett AK, Littlewood T, et al. A phase 2 trial of the FLT3 inhibitor lestaurtinib (CEP701) as first-line treatment for older patients with acute myeloid leukemia not considered fit for intensive chemotherapy. Blood. 2006;108(10):3262-3270.

29. Roboz GJ, Giles FJ, List AF, et al. Phase 1study of PTK787/ZK 222584, a small molecule tyrosine kinase receptor inhibitor, for the treatment of acute myeloid leukemia and myelodysplastic syndrome. Leukemia. 2006;20(6):952-957.

30. Tong FK, Chow S, Hedley D. Pharmacodynamic monitoring of BAY 43-9006 (Sorafenib) in phase I clinical trials involving solid tumor and AML/MDS patients, using flow cytometry to monitor activation of the ERK pathway in peripheral blood cells. Cytometry B Clin Cytom. 2006;70(3):107-114.

31. O'Farrell AM, Yuen HA, Smolich B, et al. Effects of SU5416, a small molecule tyrosine kinase receptor inhibitor, on FLT3 expression and phosphorylation in patients with refractory acute myeloid leukemia. Leuk Res. 2004;28(7):679-689.

32. O'Farrell AM, Foran JM, Fiedler W, et al. An innovative phase I clinical study demonstrates inhibition of FLT3 phosphorylation by SU11248 in acute myeloid leukemia patients. Clin Cancer Res. 2003;9(15): 5465-5476.

33. Kelly LM, Yu JC, Boulton CL, et al. CT53518, a novel selective FLT3 antagonist for the treatment of acute myelogenous leukemia (AML). Cancer Cell. 2002;1(5):421-432.

34. Fiedler W, Mesters R, Tinnefeld H, et al. A phase 2 clinical study of SU5416 in patients with refractory acute myeloid leukemia. Blood. 2003;102(8):2763-2767.

35. Considine E, Bloem L, Burkholder T, et al. LY2401401, a novel and orally bioavailable inhibitor of angiogenesis can be distinguished from other multi-targeted kinase inhibitors by its unique target selectivity profile and preclinical efficacy. Abstr 1623. Paper presented at the 98th annual meeting of the American Association for Cancer Research, April 14-18, 2007, Los Angeles, CA.

36. Quentmeier H, Reinhardt J, Zaborski M, Drexler HG. FLT3 mutations in acute myeloid leukemia cell lines. Leukemia. 2003;17(1):120-124.

37. Kuang SQ, Bai H, Fang ZH, et al. Aberrant DNA methylation and epigenetic inactivation of Eph receptor tyrosine kinases and ephrin ligands in acute lymphoblastic leukemia. Blood. 2010;115(12): 2412-2419.

38. Bueno L, de Alwis DP, Miles C, Glatt S, Trocóniz IF. Semi-mechanistic modelling of the tumour growth inhibitory effects of a new antiangiogenic drug. Abstr 1474. Paper presented at: PAGE: Population Approach Group Europe meeting, 23-26 June, 2009, St. Petersburg, Russia. Abstr 1474

39. Brunning RD, Matutes E, NL H. Acute Myeloid Leukaemia: Pathology and Genetics of Tumours of Hematopoietic and Lymphoid Tissues. Vol 3. Lyon, France: IARC Press; 2001.

40. Gorski JC, Huang SM, Pinto A, et al. The effect of echinacea (Echinacea purpurea root) on cytochrome P450 activity in vivo. Clin Pharmacol Ther. 2004;75(1):89-100.

41. Wang Z, Gorski JC, Hamman MA, Huang SM, Lesko LJ, Hall SD. The effects of St John's wort (Hypericum perforatum) on human cytochrome P450 activity. Clin Pharmacol Ther. 2001;70(4):317-326.

42. Zhou H, Tong Z, McLeod JF. "Cocktail” approaches and strategies in drug development: Valuable tool or flawed science? J Clin Pharmacol. 2004;44(2):120-134

43. Zhu B, Ou-Yang DS, Chen XP, et al. Assessment of cytochrome P450 activity by a five-drug cocktail approach. Clin Pharmacol Ther. 2001;70(5):455-461.

44. Atallah E, Cortes J, O'Brien S, et al. Establishment of baseline toxicity expectations with standard frontline chemotherapy in acute myelogenous leukemia. Blood. 2007;110(10): 3547-3551.

45. Shults K, Flye L, Green L, Daly T, Manro JR, Lahn M. Patient-derived acute myeloid leukemia (AML) bone marrow cells display distinct intracellular kinase phosphorylation patterns. Cancer Manag Res. 2009;1:49-59.
46. Cheson BD, Bennett JM, Kopecky KJ, et al. Revised recommendations of the International Working Group for Diagnosis, Standardization of Response Criteria, Treatment Outcomes, and Reporting Standards for Therapeutic Trials in Acute Myeloid Leukemia. J Clin Oncol. 2003; 21(24):4642-4649.

47. Bello CL, Mulay M, Huang X, et al. Electrocardiographic characterization of the QTc interval in patients with advanced solid tumors: Pharmacokinetic- pharmacodynamic evaluation of sunitinib. Clin Cancer Res. 2009;15(22):7045-7052.

48. International Conference on Harmonisation E14 F. Guidance for Industry E14: The clinical evaluation of QT/QTc interval prolongation and proarrhythmic potential for non-antiarrhythmic drugs. Available from: http://www.fda.gov/ohrms/dockets/ac/03/briefing/3956B3951_3902_ FDA-Preliminary\%3920Concept.doc. Accessed April 07, 2011.

49. Hall AP, Westwood FR, Wadsworth PF. Review of the effects of antiangiogenic compounds on the epiphyseal growth plate. Toxicol Pathol. 2006;34(2):131-147.

50. Moss KG, Toner GC, Cherrington JM, Mendel DB, Laird AD. Hair depigmentation is a biological readout for pharmacological inhibition of KIT in mice and humans. J Pharmacol Exp Ther. 2003;307(2): 476-480.

51. Crean S, Boyd DM, Sercus B, Lahn M. Safety of multi-targeted kinase inhibitors as monotherapy treatment of cancer: A systematic review of the literature. Curr Drug Saf. 2009;4(2):143-154.

52. Burkholder TP, Clayton JR, Rempala ME, et al. Discovery of LY2457546: A multi-targeted anti-angiogenic kinase inhibitor with a novel spectrum of activity and exquisite potency in the acute myelogenous leukemiaFlt-3-internal tandem duplication mutant human tumor xenograft model. Invest New Drugs. March 1, 2011. [Epub ahead of print].

53. Mendel DB, Laird AD, Xin X, et al. In vivo antitumor activity of SU11248, a novel tyrosine kinase inhibitor targeting vascular endothelial growth factor and platelet-derived growth factor receptors: Determination of a pharmacokinetic/pharmacodynamic relationship. Clin Cancer Res. 2003;9(1):327-337.

54. Morimoto AM, Tan N, West K, et al. Gene expression profiling of human colon xenograft tumors following treatment with SU11248, a multitargeted tyrosine kinase inhibitor. Oncogene. 2004;23(8): $1618-1626$

55. Strumberg D, Richly H, Hilger RA, et al. Phase I clinical and pharmacokinetic study of the Novel Raf kinase and vascular endothelial growth factor receptor inhibitor BAY 43-9006 in patients with advanced refractory solid tumors. J Clin Oncol. 2005;23(5):965-972.

56. Houk BE, Bello CL, Kang D, Amantea M. A population pharmacokinetic meta-analysis of sunitinib malate (SU11248) and its primary metabolite (SU12662) in healthy volunteers and oncology patients. Clin Cancer Res. 2009;15(7):2497-2506.

57. Peng B, Lloyd P, Schran H. Clinical pharmacokinetics of imatinib. Clin Pharmacokinet. 2005;44(9):879-894.

58. Van Erp NP, Gelderblom H, Guchelaar HJ. Clinical pharmacokinetics of tyrosine kinase inhibitors. Cancer Treat Rev. 2009;35(8): 692-706.

59. Cheung C, Gonzalez FJ. Humanized mouse lines and their application for prediction of human drug metabolism and toxicological risk assessment. J Pharmacol Exp Ther. 2008;327(2):288-299.

60. Gonzalez FJ. CYP3A4 and pregnane X receptor humanized mice. J Biochem Mol Toxicol. 2007;21(4):158-162.

61. Gonzalez FJ, Yu AM. Cytochrome P450 and xenobiotic receptor humanized mice. Annu Rev Pharmacol Toxicol. 2006;46:41-64.

62. Felmlee MA, Lon HK, Gonzalez FJ, Yu AM. Cytochrome P450 expression and regulation in CYP3A4/CYP2D6 double transgenic humanized mice. Drug Metab Dispos. 2008;36(2): $435-441$.

63. Quinney SK, Galinsky RE, Jiyamapa-Serna VA, et al. Hydroxyitraconazole, formed during intestinal first-pass metabolism of itraconazole, controls the time course of hepatic CYP3A inhibition and the bioavailability of itraconazole in rats. Drug Metab Dispos. 2008;36(6):1097-1101. 
64. Polster CS, Atassi F, Wu S-J, Sperry DC. Use of artificial stomachduodenum model for investigation of dosing fluid effect on clinical trial variability. Mol Pharm. 2010;7(5):1533-1538.

65. Curigliano G, Spitaleri G, Fingert HJ, et al. Drug-induced QTc interval prolongation: A proposal towards an efficient and safe anticancer drug development. Eur J Cancer. 2008;44(4):494-500.

66. Crouch MA, Limon L, Cassano AT. Clinical relevance and management of drug-related QT interval prolongation. Pharmacotherapy. 2003;23(7):881-908.

67. Gojo I, Jiemjit A, Trepel JB, et al. Phase 1 and pharmacologic study of MS-275, a histone deacetylase inhibitor, in adults with refractory and relapsed acute leukemias. Blood. 2007;109(7):2781-2790.
68. Illmer T, Ehninger G. FLT3 kinase inhibitors in the management of acute myeloid leukemia. Clin Lymphoma Myeloma. 2007;8 Suppl 1: S24-S34.

69. Jennings CD, Foon KA. Recent advances in flow cytometry: Application to the diagnosis of hematologic malignancy. Blood. 1997;90(8): 2863-2892.

70. Bardet V, Tamburini J, Ifrah N, et al. Single cell analysis of phosphoinositide 3-kinase/Akt and ERK activation in acute myeloid leukemia by flow cytometry. Haematologica. 2006;91(6):757-764.

71. Chow S, Minden MD, Hedley DW. Constitutive phosphorylation of the S6 ribosomal protein via mTOR and ERK signaling in the peripheral blasts of acute leukemia patients. Exp Hematol. 2006;34(9):1182. 


\section{Supplementary figures}

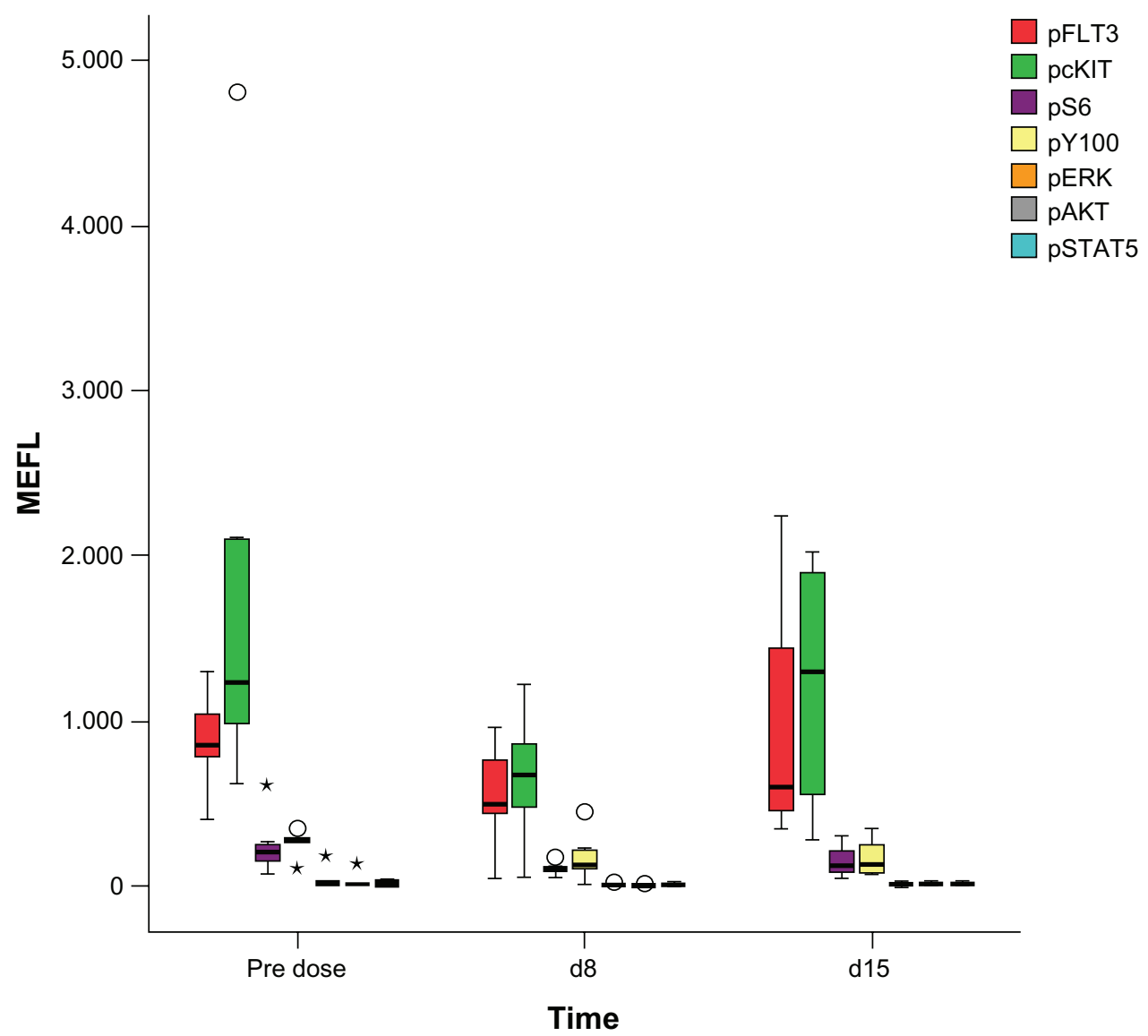

Figure SI Flow cytometric assessment of phosphoproteins (pFLT3, pCKIT, pS6, pYI00, pERK, pAkt, and pSTAT5) in peripheral CD34+CDII- blood cells of five patients treated with a single dose and multiple doses of LY2457546. Summary representation of all five patients for pFLT3 (red), pcKIT (green), pS6 (pink), and pYI00 (yellow) at predose, and after 8 and I5 days of treatment with LY2457546. Reduction of pFLT3, pcKIT and pS6 at day 8 was observed in most patients, which increased at day I5. pERK (orange), pAKT (gray), and pSTAT5 (cyan) expression was not detectable. Phosphoprotein expression is plotted as MEFL.

Abbreviation: MEFL, molecules of equivalent fluorescence. 


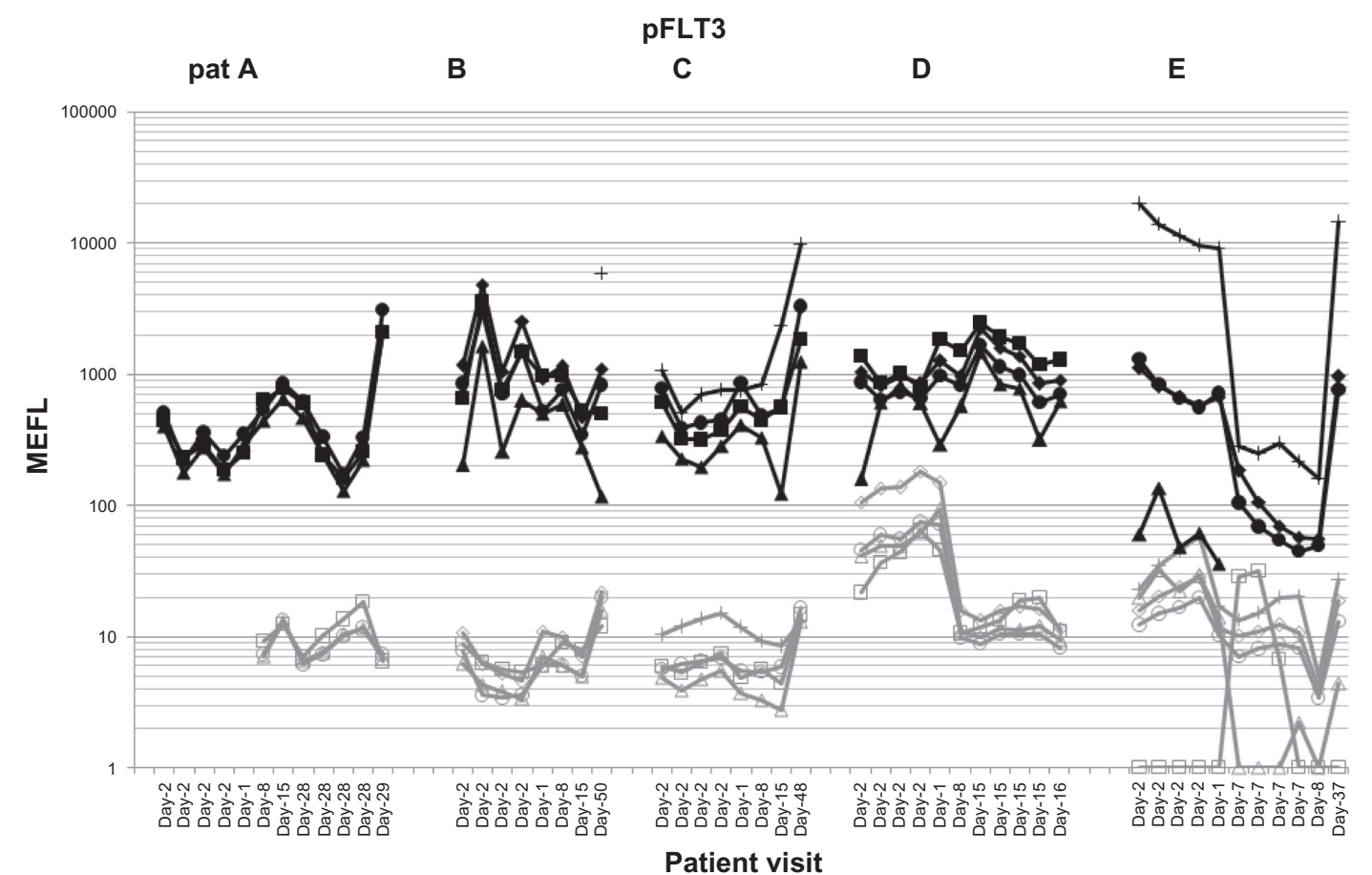

Figure S2 Differentiation of isotype control and pFLT3 detection in five AML patients by flow cytometry. Each patient (A-E) is shown for their pFLT3 expression in

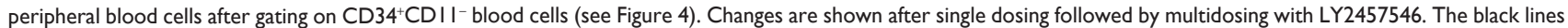
represent PFLT3 expression as detected by MEFL, while the gray lines represent the respective isotype control.

Abbreviations: AML, acute myeloid leukemia; MEFL, molecules of equivalent fluorescence.

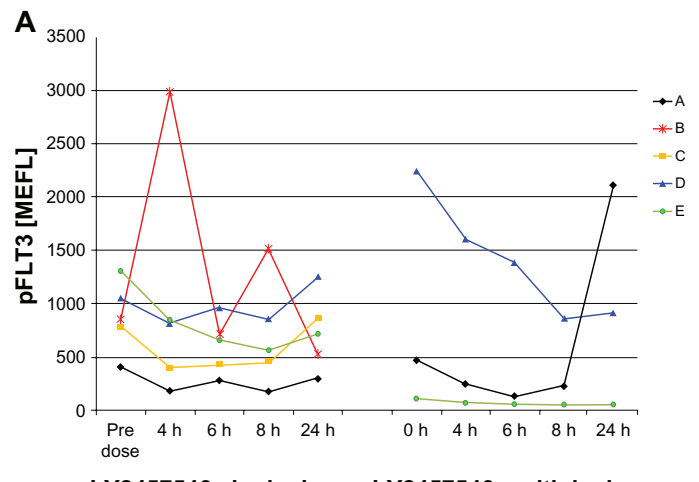

LY2457546 single dose LY2457546 multiple dose

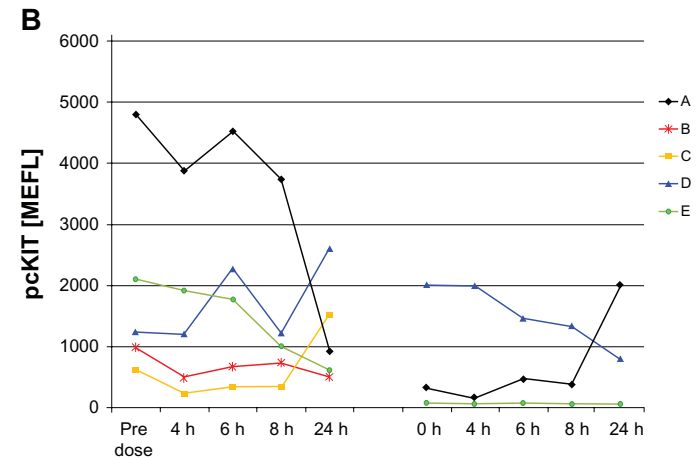

LY2457546 single dose LY2457546 multiple dose

C

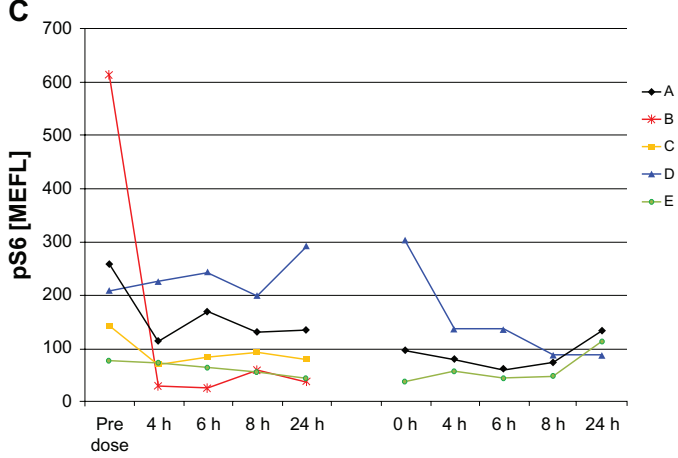

LY2457546 single dose LY2457546 multiple dose

Figure S3 Flow cytometric assessment of pFLT3, pcKIT, and pS6 in patients treated with a single dose followed by multiple doses of LY2457546 in peripheral CD34+CDI Iblood cells. Individual pharmacodynamic profiles of pFLT3 (A), pcKIT (B), and pS6 (C) expression following single-dose and multiple-dose LY2457546. Phosphoprotein expression is presented as MEFL. Reduction of phosphoprotein expression begins four hours after administration of LY2457546.

Abbreviation: MEFL, molecules of equivalent fluorescence. 


\section{Patient A}

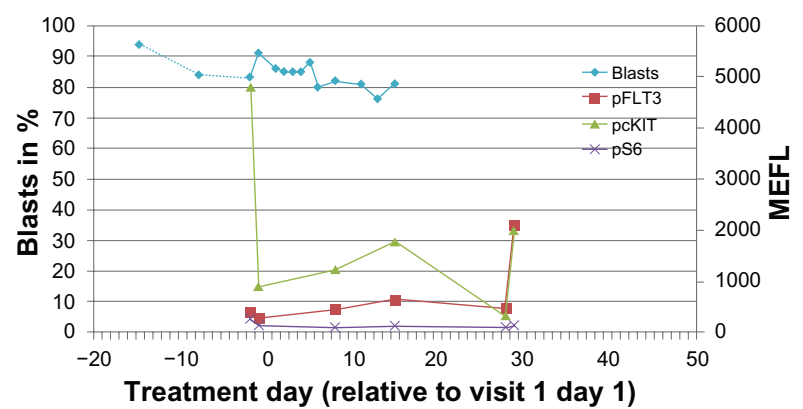

Patient C

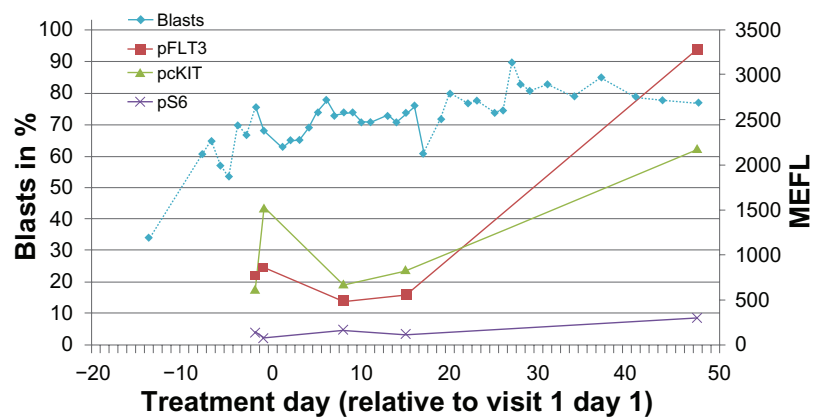

Patient B

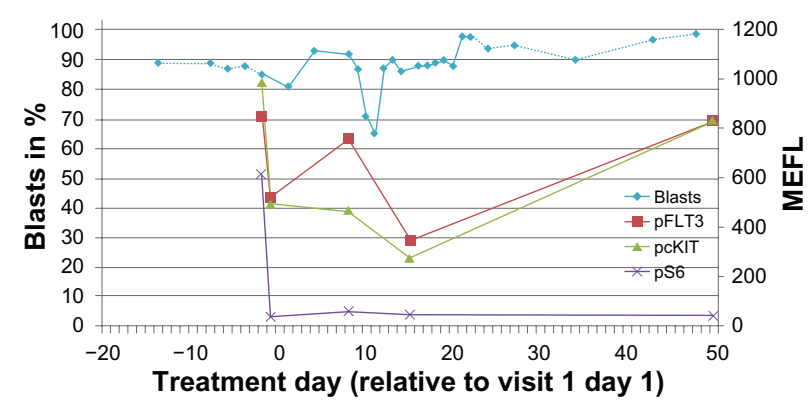

Patient D

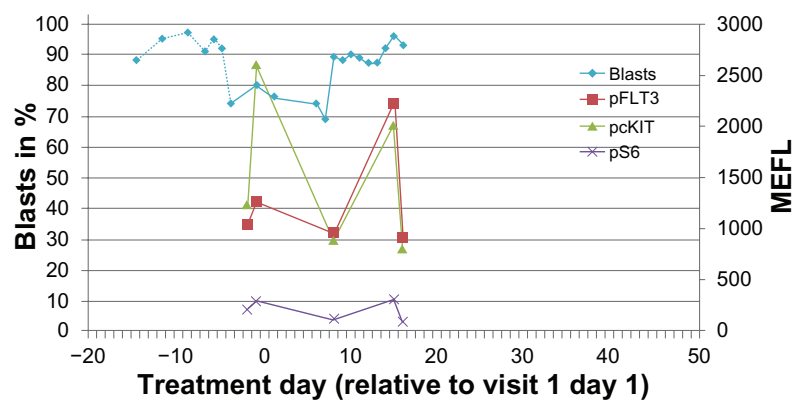

Patient E

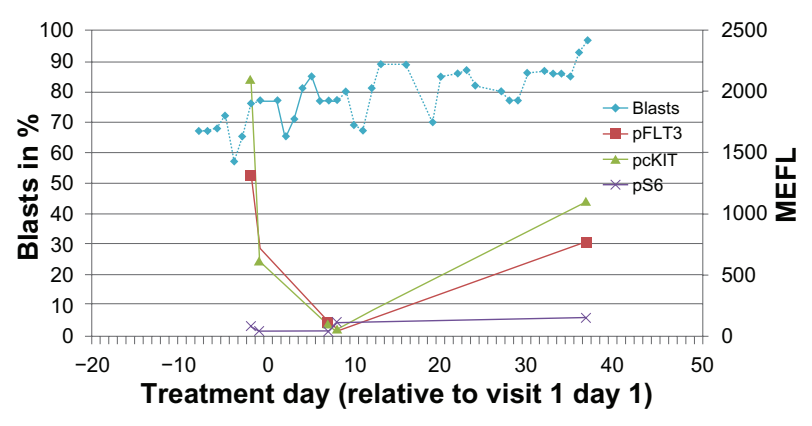

Figure S4 Flow cytometric assessment of pFLT3, pcKIT, and pS6 in peripheral CD34+CDI I- blood cells relative to blast cell counts for patients (A-E) following administration of LY2457546. Expression of pFLT3, pcKIT, and pS6 at predose, day I, day 8, day 15, and at the end of the study was measured in peripheral CD34+CDII- blood cells by fluorescence activated cell sorting. Expression of phosphoproteins as detected by MEFL for individual patients. Patients (A-E) are shown in relationship to blast counts. Solid lines of blast counts indicate dosing period with LY2457546 while dotted lines of blast counts indicate time periods without LY2457546.

Abbreviation: MEFL, molecules of equivalent fluorescence.

\section{Publish your work in this journal}

Cancer Management and Research is an international, peer-reviewed open access journal focusing on cancer research and the optimal use of preventative and integrated treatment interventions to achieve improved outcomes, enhanced survival and quality of life for the cancer patient The journal welcomes original research, clinical \& epidemiological studies, reviews \& evaluations, guidelines, expert opinion \& commentary, case reports \& extended reports. The manuscript management system is completely online and includes a very quick and fair peerreview system, which is all easy to use. Visit http://www.dovepress.com/ testimonials.php to read real quotes from published authors. 